\title{
LA LEGISLACIÓN ARCHIVÍSTICA EN AMÉRICA LATINA
}

\author{
Luis Fernando Jaén García ${ }^{1}$
}

\begin{abstract}
RESUMEN
El artículo centra su atención en el análisis de las diferentes disposiciones legales en materia archivística de los países de América Latina. Su tratado enmarca todos aquellos preceptos jurídicos vigentes hasta junio de 1999, que tienen relación directa con el mundo de los archivos del área geográfica en estudio. De los cuáles destacan los tres tipos de disposiciones que se analizan en este trabajo, a saber, las correspondientes a los Archivos Nacionales o Archivos Generales de la Nación, de los Sistemas Nacionales de Archivos y de carácter específico.
\end{abstract}

\section{PALABRAS CLAVES}

Legislación archivística, Sistema Nacional de Archivos, América Latina, leyes específicas sobre archivos.

\section{1- INTRODUCCIÓN}

El desarrollo autóctono de las poblaciones de América se vieron seriamente truncadas cuando fueron forzosamente introducidas en la corriente histórica mundial, a partir de finales del siglo XV y principios del XVI, por las potencias europeas de la época, a saber, España, Inglaterra, Francia y Portugal. La expansión colonial imperialista de esos países condujo al desmantelamiento de las estructuras vernáculas y, con ello, la imposición de un nuevo sistema político, económico, social, institucional, religioso y cultural.

El devenir de esos acontecimientos propició la división del continente en dos grandes sectores, desde el punto de vista geopolítico y cultural, América Anglosajona y América Latina. La primera, compuesta por Canadá y Estados Unidos, su origen evoca a la colonización inglesa, que neutralizó en algunas zonas a la francesa y española. La

\footnotetext{
1 Costarricense. Diplomado en Archivo Administrativo, bachiller y licenciado en Historia por la Universidad de Costa Rica. Actualmente estudia un Doctorado en Documentación en la Universidad Carlos III de Madrid, España. Profesor en la Sección de Archivística de la Escuela de Historia de la Universidad de Costa Rica.
} 
segunda, integrada por los países al sur de río Bravo, sobre la inmensa mayoría de los cuales se extendió el dominio de los países ibéricos, España y Portugal.

El territorio continental de América Latina está constituido geopolíticamente por los países comprendidos desde el río Bravo en México hasta la Tierra del Fuego en Argentina. A su vez, está dividido en tres grandes áreas, América del Norte, América Central y América del Sur. Por su parte, la zona insular del continente corresponde a lo que se conoce como el Caribe, integrado por las Antillas Mayores y Antillas Menores. En la región se han ejercido múltiples procesos de síntesis, sumas y amalgamas, y se ha delineado una identidad peculiar como resultado de la participación plural y conjunta de las culturas indígenas, europeas y africanas ${ }^{2}$.

Estos países que poseen una historia afín, una trayectoria administrativa similar, unas raíces culturales análogas, una problemática y sufrimiento semejante, también comparten la particularidad de tener una situación e inquietudes archivísticas en común.

Uno de los problemas, entre otros tantos, que afrontan los archivos latinoamericanos es lo referente a su legislación en materia archivística; en unos casos la falta de ésta, en otros, su obsolescencia. Las disposiciones legales garantizan, de alguna manera, la puesta en marcha de un conjunto de políticas encaminadas a la actuación, desarrollo y consolidación de los archivos. Es el hilo conductor por medio del cual se rige el quehacer archivístico de una nación, por lo tanto, la base legal es el elemento clave para que se ordenen determinados planteamientos y sirva de respaldo y garantía a las acciones que se desarrollan.

En los países latinoamericanos podemos distinguir cuatro niveles en la legislación archivística, a saber, del Sistema Nacional de Archivo (SNA), referente a al Archivo Nacional (AN) o Archivo General de la Nación (AGN), de ámbito regional y de carácter específico.

La legislación correspondiente a los SNA tiene una mayor amplitud, a razón de que engloba la totalidad de los archivos de una Nación que formen parte de él. Lo cual fundamenta las directrices generales para éstos, encaminado a un mejor aprovechamiento de los planteamientos y su puesta en práctica. Es condición básica,

2E. Morales. América Latina y el Caribe, 1997, pág. 114. 
para tal efecto, que exista un ente rector que planifique, ejecute, dirija, controle y evalúe, las políticas o disposiciones que dicte el Sistema en materia archivística y áreas conexas que lo afecten directamente.

Las leyes de creación y funcionamiento de los AN o AGN, por su propensión y en algunos casos- por falta de una ley más íntegra, tienen determinadas incidencias directa o indirecta- en otros archivos. Por lo tanto, sus planteamientos se pueden extrapolar, en algunos aspectos, a los demás archivos del país -desde luegoadaptándolos a su realidad y necesidades inmediatas.

Las leyes de carácter regional se presentan en aquellos países con gobiernos descentralizados que, por su condición, pueden legislar en un entorno local. Por lo tanto, su aplicación corresponde a un sector y un área de acción muy concreta. Afecta a los archivos de un espacio geográfico en particular y no a todos en su conjunto.

Las leyes de carácter específico son aquellas que por su propiedad regulan aspectos muy precisos del ámbito archivístico; éstas pueden estar relacionadas con el expurgo, la transferencia, los documentos, la conservación y las etapas del archivo, entre otras.

La delimitación espacial del trabajo se circunscribe en el análisis de la legislación archivística de los países de América Latina y el Caribe. En el plano temporal se restringió a las disposiciones legales vigentes hasta junio de 1999, fecha en que se finalizó este artículo; por lo tanto, nos encontramos con casos extremos como disposiciones promulgadas en la década de los 20, hasta las más recientes que corresponden a los 90 .

Las fuentes que se utilizaron para la realización del trabajo fueron, principalmente, las leyes en materia archivística de los países en estudio. Las cuales están recopiladas en varios volúmenes que editó el Consejo Internacional de Archivos, mediante la Revista Archivum. Éstas publicaciones recogen toda la legislación archivística mundial y se encuentra distribuida en los volúmenes siguientes: XVII de 1971, XIX de 1972, XX de 1972, XXI de 1973, XXVIII de 1982, XL de 1995 y XLI de 1996. 
La revista en cuestión reproduce las leyes tal como fueron promulgadas por sus respectivos países, en algunos casos -de menor proporción- lo que se publica es un compendio de éstas. Para reforzar ese vacío, en los casos correspondientes, se recurrió a otras fuentes donde también se reproducen las leyes; éstas se localizaron en revistas especializadas sobre Archivística en América Latina, como la Revista ALA (Colombia) y la Revista SED (México).

Además, se consultaron otras publicaciones especiales sobre la legislación, editadas por los AN o AGN -como los de Colombia, Costa Rica y Perú- y reproducciones de los diarios oficiales en que éstas fueron publicadas. Todas ellas se localizan en el Centro de Información y Documental de Archivos (CIDA) de España.

La investigación fue complementada con fuentes bibliográficas, para reforzar aquellos planteamientos teóricos, las cuales aparecen recogidos en la parte reservada a la bibliografía de este trabajo.

En párrafos anteriores, señalamos que en el área geográfica en estudio existen cuatro niveles de legislación archivística. En este artículo nos hemos limitado a estudiar únicamente las disposiciones relativas a tres de ellas, a saber:

- Las leyes de los SNA, porque presentan la particularidad de legislar en el ámbito nacional todos aquellos archivos que formen parte de él.

- Las legislaciones de los AN o AGN porque, a parte de legislar para ellos, en algunos casos tienen una vinculación directa o indirecta con el resto de los archivos, sobre todo cuando no existe una ley que rija para todos.

- Las leyes de carácter específico, porque a pesar de ser atinentes a un aspecto delimitado, tienen un mayor alcance ya que sus planteamientos afectan a diversos archivos.

Hemos omitido las leyes de ámbito regional porque consideramos que presentan una realidad muy concreta y su incidencia se circunscribe en un entorno geográfico en particular. Además, su proyección no afecta a todos los archivos de un país. La hemos considerado, en fin, fuera de los límites de este trabajo. 
El criterio a tener en cuenta para la elección de los países obedeció a que ellos deberían detentar, por lo menos, alguna de las disposiciones legales supracitadas. Posteriormente se realizó una separación por áreas, según la división geopolítica del territorio objeto de estudio, con sus respectivos países -previamente seleccionados- en total fueron dieciocho, a saber:

- América del Norte: México.

- América Central: Costa Rica, Guatemala, Nicaragua y Panamá.

- América del Sur: Argentina, Bolivia, Brasil, Colombia, Chile, Ecuador, Paraguay, Perú, Uruguay y Venezuela.

- Las Antillas: Cuba, Puerto Rico y República Dominicana.

La anterior agrupación nos permitió distinguir cual es la situación que presenta cada una de las regiones y, por ende, sus países, en el ámbito de la legislación archivística.

El trabajo está dividido en dos parte. En la primera se establecieron todas las legislaciones que con anterioridad se había determinado estudiar; pero el análisis está orientado, únicamente, en las leyes de los AN o AGN y las de carácter específico. Las del SNA son analizadas por separado, pues consideramos oportuno darle ese tratamiento por la función que ejerce en el contexto archivístico de un país. La segunda parte corresponde al estudio de los Sistema. Dándole énfasis a las líneas de actuación, las clases de archivos que lo comprenden, las funciones encomendadas y en general las directrices que desarrollan para el mejoramiento y fortalecimiento de los archivos. 
2- PRIMER PARTE: LAS LEYES DE LOS ARCHIVOS NACIONALES O ARCHIVOS GENERALES DE LA NACIÓN Y LAS DE CARÁCTER ESPECÍFICO

La legislación en su máxima acepción es el conjunto o cuerpo de leyes por las cuales se gobierna un Estado, o una materia determinada ${ }^{3}$. Es la mayor autoridad, acorde con la constitución política de una Nación, por medio de la cual se preceptuan una serie de disposiciones.

Partiendo de la citada definición y, adaptándola a nuestra área, se puede decir que la legislación archivística es el conjunto de leyes que normalizan y controlan las políticas archivísticas de un país. Palacios Preciados y Arias Roca señalan que es un corpus normativo de máximo nivel y actualizado que regula de modo integral las diversas facetas inherentes al tratamiento de los documentos en todas las fases de su ciclo vital y que estructura la organización y funcionamiento de sus respectivos sistemas nacionales de $\operatorname{archivos}^{4}$.

Las leyes sobre archivística son imprescindibles en un Estado de derecho porque ordenan la aplicación de las normativas en los archivos y, por tal, el valor legal, administrativo, fiscal, informativo y cultural de los documentos. Es evidente que la preocupación por la legislación se origina por la naturaleza jurídica, probatoria y testimonial de éstos, a partir de las estructuras políticas y administrativas de una Nación.

Lejos de ser un fin en sí misma, la legislación archivística constituye un medio para lograr propósitos administrativos y sociales. Favorece la modernización de los archivos porque permite, garantiza y respalda todos aquellos procesos vinculados con el tratamiento de la documentación. Es garante del cumplimiento de una serie de normas establecidas para su correcto desempeño.

Si bien es cierto que las disposiciones legales aseguran la puesta en marcha de las políticas archivísticas, muchas de éstas se ven mutiladas por la falta de apoyo, interés y decisión de los gobernantes de turno. Lo cual es producto de una falta de concienciación de la razón de ser de los archivos, de su importancia en el proceso

\footnotetext{
${ }^{3}$ Real Academia Española. Diccionario de la Lengua Española, 1992, pág. 1240.

${ }^{4}$ J. Palacios Preciado; V. Arias Roca. América Latina y el Caribe, 1997, pág. 177.
} 
productivo del país y para hacer más transparente la gestión pública, entre otras; de cara a contribuir y consolidar el sentido de pertenencia de la comunidad nacional.

Por lo tanto, los archivos son auténticos centros de información, imprescindibles para la administración y esenciales para la cultura. Permiten que la relación entre el Estado y la sociedad sea más dinámica e integral y, por ende, haya un mayor grado de compromiso y solidaridad entre sus miembros.

En la mayoría de los países de América Latina esta legislación tiene su origen en el período colonial. Los primeros intentos y preocupación por legislar lo concerniente a las disposiciones de los archivos datan de esa época. Situación que se va afianzando a partir de la emancipación y con la constitución de los estados nacionales.

Las primeras instrucciones tienen una vinculación directa con la creación de los archivos nacionales, en estrecha relación con el pensamiento político de la época, es decir, legitimar los derechos del Estado y dotar a los ciudadanos de elementos e instituciones para reforzar su nacionalismo.

En esta parte se analizan todas aquellas leyes referentes a los AN o AGN y las de carácter específico, las cuales están divididas por áreas geográficas -América del Norte, América Central, América del Sur y las Antillas- con sus correspondientes países.

\subsection{AMÉRICA DEL NORTE}

México es el único país de América del Norte que forma parte del área geográfica continental de América Latina, cuya división natural está definida por el río Bravo.

Durante la época colonial la Nueva España fue, si duda, la joya más preciada de los dominios españoles, a razón de su facilidad de acceso a través del Atlántico, por haber sido la primera posesión de gran importancia en el continente, por su proximidad a las Antillas, por sus riquezas naturales y minerales y por su extensión, entre otras. 


\subsubsection{LA LEGISLACIÓN ARCHIVÍSTICA EN MÉXICO}

Los cimientos de la legislación archivística mexicana se remontan a la época de sometimiento español. Conscientes, las autoridades coloniales, de la necesidad e importancia de organizar la documentación, en 1790, fue autorizada la creación del Archivo General del Virreinato de la Nueva España.

En 1792 promulgaron el primer reglamento. Establecía que los documentos anteriores a 1766 serían remitidos al archivo y que en lo sucesivo, al final de cada década, fueran transferidos todos los que tuvieran más de treinta años de haber sido producidos.

El AGN fue creado en 1823, al cual se le integró toda la documentación del Virreinato y de las nuevas instituciones que nacen a raíz de la formación del Estado.

En 1846 aparece el segundo reglamento del AGN. Dispone que éste pasará a depender del Ministerio de Relaciones. Además, determina que los documentos serán clasificados y ordenados separándolos en anteriores y posteriores a la independencia; es evidente la primacía de los criterios historicistas para organizar el archivo.

\subsubsection{ACUERDO DE 24 DE ABRIL DE 1980 ARCHIVO GENERAL DE LA NACIÓN}

El 24 de abril de 1980 se promulgó el acuerdo sobre el AGN. Establece que es la institución encargada del manejo de los archivos administrativos e históricos del sector público; a tenor de lo que estipula el art. 1: "El Archivo General de la Nación, como órgano desconcentrado de la Secretaría de Gobernación, será la entidad central $y$ de consulta del Ejecutivo Federal en el manejo de los archivos administrativos e históricos de la Administración Pública Federal, para lograr una mayor coordinación, eficiencia y uniformidad normativa en esta materia"5.

Para lograr una mejor coordinación y equilibrio en las políticas archivísticas, le confiere nuevos cargos al AGN. De ellos destacamos el interés por determinar los

${ }^{5}$ Archivum, 1982, pág. 262. 
elementos que permitan una sobresaliente eficiencia de los archivos federales. Además, el empeño por normalizar las operaciones internas y externas de éstos, lo cual se refuerza con la gestión de apoyo y asesoramiento para el manejo y administración de documentos.

Los procesos técnicos archivísticos de conservación, transferencia y eliminación, serán supervisados -para su fiel cumplimiento- por el AGN. Además, éste deberá preservar toda la documentación que le remitan las entidades de la administración pública federal.

\subsection{AMÉRICA CENTRAL}

El territorio de América Central se extiende entre el istmo de Tehuantepec, al sur de México, hasta la región del Darién, en Panamá. Comprende una extensión de más de medio millón de kilómetros cuadrados y es el puente geográfico que une América del Norte con América del Sur.

Esta área reúne a una serie de países de antigua colonización española, Guatemala, Honduras, El Salvador, Nicaragua, Costa Rica y Panamá; a los que se les ha unido un país marcado por el asentamiento inglés, Belice.

Hasta principios del siglo XIX las provincias del Istmo estuvieron reunidas bajo la Capitanía General de Guatemala ${ }^{6}$. El 15 de setiembre de 1821 se proclamó la independencia de las colonias; después de la emancipación comenzó un proceso para lograr la unión de las nuevas naciones en sólo estado, la Federación Centroamericana. Las divergencias políticas y los intereses particulares, entre otros, provocó la disgregación; aunque hoy día persiste el interés por la unificación de los países ístmicos.

\subsubsection{LA LEGISLACIÓN ARCHIVÍSTICA EN COSTA RICA}

La legislación archivística costarricense tiene su origen después de la emancipación. A pesar de que durante la dominación española se manifestó el interés

\footnotetext{
${ }^{6}$ Salvo Panamá que perteneció al Virreinato de Nueva Granada.
} 
por la organización de la documentación de las instituciones coloniales, no se legisló al respecto. Pero, esa previsión permitió que hoy día se conserve gran parte de la documentación, generada y recibida durante esa etapa, en el AN; tales como, actas de los ayuntamientos, mortuales y protocolos, entre otros.

A partir de la independencia, 15 de setiembre de 1821, es más notable la preocupación por conservar organizadamente los documentos que testimonian el pasado y presente de esa Nación. En 1824 se creó el Archivo de la Asamblea Constituyente, en 1834 el Archivo Judicial, en 1859 los Archivos Judiciales en las capitales de provincias, en 1878 la Oficina de Archivos Judiciales y en 1881 el Archivo Nacional.

En el siglo XIX se promulgaron diversas leyes y decretos vinculados directamente con la creación de archivos. A saber, el decreto 13 -de 29 de agosto de 1859- crea el Archivo Judicial de las Ciudades Capitales de Provincias; el decreto 23 de 14 de julio de 1881- ordena a los jueces a organizar sus archivos mientras se constituían la oficina para archivos públicos de todo el país y el decreto 25 -de 23 de julio de 1881- dio origen al AN.

Durante el siglo XX se continúa legislando en la materia, fue promulgada la ley 34, de 21 de diciembre de 1934, que autoriza el timbre de archivos, cuyos fondos se emplearían para construir el edificio del AN. El decreto 64, de 12 de agosto de 1936, fundó la Revista del Archivo Nacional, como medio de difusión de la investigación histórica, archívistica y de las fuentes del archivo.

Por otra parte, la ley 3661, de 10 de enero de 1966, regulaba el funcionamiento del AN y establecía sus responsabilidades. Además tenía la particularidad de que legislaba, tímidamente, sobre aspectos concernientes a un futuro sistema de archivos; a razón de que, según Chacón Arias, se le atribuía la obligación de inspeccionar regularmente los archivos administrativos del Poder Ejecutivo y de participar activamente, ya preparando funcionarios responsables de esos archivos, ya fiscalizando sus transferencias al AN, ya autorizando la destrucción de papeles considerados sin importancia de ninguna especie ${ }^{7}$.

${ }^{7}$ V. Chacón. Costa Rica mira por el telescopio, 1997, pág. 11. 
En otro orden de cosas, la ley 5574 -de 6 de setiembre de 1974- estableció la Junta Administrativa del Archivo Nacional (JAAN) y el decreto 4664-G de 4 de febrero de 1975, promulgó su reglamento. El decreto 12023-GC de 21 de noviembre de 1980, determinó que el AN depende jerárquicamente del Ministerio de Cultura, Juventud y Deportes. Por último, la ley 7202, de 24 de octubre de 1990, instituyó el SNA y el decreto 24023-C, de 30 de enero de 1996, dictó el reglamento a la ley; ambas están vigentes ${ }^{8}$.

\subsubsection{LA LEGISLACIÓN ARCHIVÍSTICA EN GUATEMALA}

Existe un vacío respecto a los antecedentes legales en materia archivística de este país, por cuanto las fuentes consultadas no brindaron ninguna información al respecto. No se pudo localizar otras que proporcionaran esos datos.

\subsubsection{DECRETO 1768 REGLAMENTO DEL ARCHIVO GENERAL DE LA NACIÓN}

El decreto 1768, de 25 de junio de 1968, concerniente al reglamento del AGN, señala su cambio de nombre por el de Archivo General de Centro América (AGCA). El cual funcionará como institución del Estado de Guatemala y dependerá del Ministerio de Educación Pública.

El profesor Cruz Mundet señala que la transferencia o remisión de documentos es el conjunto de procedimientos mediante los cuales la documentación es remitida de una etapa a otra del archivo 9 . Actuación que es contemplada en el decreto, a razón de lo que establece el art. 9: “Todas las dependencias públicas del Estado central y sus entidades descentralizadas, autónomas y semiautónomas, están en la obligación de enviar al Archivo General de Centro América la documentación debidamente organizada y encuadernada"10.

También el AGCA tiene la función de destruir la documentación considerada carente de valor histórico y administrativo, con la anuencia del Consejo Consultivo y

${ }^{8}$ Éstas dos últimas leyes serán analizadas en la segunda parte.

${ }^{9}$ J. R. Cruz Mundet. Manual de Archivística, 1996, pág. 190. 
previa autorización del Ministerio de Educación Pública. El decreto no especifica cuál es papel que desempeña ese Consejo ni quienes lo integran.

\subsection{LA LEGISLACIÓN ARCHIVÍSTICA EN NICARAGUA}

Las disposiciones legales que han marcado la política archivística nicaragüense es muy limitada. El decreto de 28 de abril de 1888 estableció el reglamento del AN. El Archivo General de la República, fue creado en 1896, su función primordial era recibir todos los "archivos del país"; éste dependía del Ministerio de Instrucción Pública.

\subsubsection{DECRETO 401 FUNCIONAMIENTO DEL ARCHIVO GENERAL DE LA NACIÓN}

El decreto 401, de 14 de octubre de 1959, regula el funcionamiento del AGN, organismo dependiente del Ministerio de Gobernación. Establece que es la institución encargada de recoger, custodiar, conservar y defender la riqueza documental de la República. Bien que se encuentren bajo resguardo de los diversos organismos y oficinas del Estado o en poder de cualquier otra persona, natural o jurídica; en éste último caso deben llegar a un acuerdo previo entre las partes.

\subsubsection{LA LEGISLACIÓN ARCHIVÍSTICA EN PANAMÁ}

Este país de América Central, presenta la particularidad que durante la sujeción española los documentos oficiales eran remitidos a Madrid y Sevilla, principalmente. Por lo tanto, es poca la información colonial que existe en el AN de Panamá. La ley 43, emitida en el año de 1912, estableció la creación de ese archivo.

${ }^{10}$ Archivum, 1971, pág. 126. 


\subsubsection{LEY DE 20 DE FEBRERO DE 1941 ARCHIVO NACIONAL}

El art. 1 de esta ley indica que en el AN "estarán todos los archivos de la Nación, de las provincias y de los municipios, de modo que puedan ser conservados y metódicamente ordenados para hacer fácil su consulta y estudio".11 Aunque no profundiza sobre los criterios por aplicar en la organización de la documentación, considera que dicho proceso es de vital importancia para acceder a la información contenida en los documentos $\mathrm{y}$, por ende, la facilitación a los clientes internos $\mathrm{y}$ externos.

Menciona, de forma lacónica, la trasferencia documental. Determina que todos los asuntos judiciales y administrativos ingresarán al AN un año después de su tramitación. Más no señala el procedimiento para realizarlo. Exceptúa de esta actividad la documentación de los ministerios del Estado y otras dependencias oficiales, abogando que por su índole requieren de mayor tiempo; pero no indica cuándo se deben transferir.

\subsubsection{LEY DE 23 DE ENERO DE 1957 ORGANIZACIÓN DE LOS ARCHIVOS NACIONALES DE LA REPÚBLICA DE PANAMÁ}

Esta ley delimita las normas para, organizar, custodiar, manejar, evaluar y facilitar el acceso y consulta de los documentos existentes en las oficinas de la República. Además, lo referente a la conservación adecuada del patrimonio documental de la Nación (PDN).

Establece una clara diferenciación entre las clases de archivos y los divide en estatales y no estatales. Los primeros, son aquellos constituidos por todas las oficinas del Estado, de organismo de gobierno y de instituciones autónomas. Los segundos, corresponden a las instituciones no pertenecientes al Estado, sin embargo, la documentación que custodian forman parte de la historia del país; entre ellos tenemos a los archivos de la iglesia católica, de partidos políticos inscritos oficialmente, de instituciones privadas de carácter cultural y benéficas, de empresas particulares y personales.

${ }^{11}$ Ibídem, pág. 146. 
El AN cuenta con una Junta Nacional de Documentación y Archivos, que tiene por misión velar por el desarrollo de las normas contenidas en la ley; podríamos decir que cumple un papel similar al de un SNA. Entre sus atribuciones destaca la aprobación o desaprobación de la eliminación de documentos; no señala los procedimientos a seguir, pero si contempla la constitución de comisiones evaluadoras en el ámbito institucional. Éstas son el órgano responsable de establecer el primer dictamen de valoración de la documentación, antes de ser elevada a la comisión nacional, para su veredicto final.

Otro aspecto por destacar es la autoridad que le confiere a la Junta para la fijación de normas de conservación, descripción, preservación y, en caso pertinente, el traslado al Estado de los archivos no estatales.

Existe un marcado interés por rescatar aquellos documentos que están fuera del radio de acción de la ley que, por su contenido e importancia para la historia del país, ameritan ser adquiridos. Para tal efecto, es necesario llegar a un acuerdo satisfactorio entre las partes y establecer las limitaciones de su acceso para salvaguardar el derecho a la intimidad.

La ley también contempla la transferencia documental, el art. 11 dispone que: “cada dependencia del Estado trasladará los archivos inactivos de valor permanente al Archivo Nacional"12. A su vez, se respetarán los períodos acordados entre los administradores de las entidades y el director general del AN y deberá contar con la aprobación de la Junta.

Cuando la documentación contenga información que aténte contra la seguridad nacional o de particulares su acceso será limitado, con el fin de proteger los derechos legales del Estado y los ciudadanos. Más no indica el tiempo que esa documentación será de uso restringido.

${ }^{12}$ Ibídem, pág. 150. 


\subsubsection{ANÁLISIS COMPARATIVO}

De las siete naciones que constituyen el Istmo, únicamente cuatro tienen alguna disposición legal concerniente al mundo archivístico; al menos así aparece registrado en las fuentes consultadas. De éstas sólo Guatemala, Nicaragua y Panamá disponen de leyes concernientes a los AN. Por su parte, Costa Rica es la única que posee un corpus normativa relacionado con el SNA; más ningún país posee algún precepto legal de carácter específico.

La mayoría de las legislaciones presentan la particularidad de haber sido promulgadas a finales de la primera mitad del siglo XX, situación que repercute en la obsolescencia de sus planteamientos. Costa Rica es la excepción, pues las leyes de este país datan de la década de los 90, cuya argumentación está más acorde con los postulados de la teoría archivística contemporánea.

El cuadro 1 refleja la posición de los países de América Central en relación con las legislaciones en materia archivística

\section{CUADRO 1}

LEGISLACIÓN ARCHIVÍSTICA DE LOS PAÍSES DE AMÉRICA CENTRAL

\begin{tabular}{|c|c|c|c|}
\hline PAIÍS & LEY DE AN O AGN & $\begin{array}{c}\text { LEYES DE CARÁCTER } \\
\text { ESPECÍFICO }\end{array}$ & LEY DEL SNA \\
\hline Costa Rica & $-\mathrm{No}$ & -No & $\begin{array}{l}- \text { Ley } 7202 \quad(24-10-92) \\
\text {-Decreto 24023-C } \\
(30-01-95)\end{array}$ \\
\hline Guatemala & -Decreto 1768 (25-06-68) & -No & -No \\
\hline Nicaragua & \begin{tabular}{|ll}
-Decreto $401 \quad(14-10-59)$ \\
\end{tabular} & $-\mathrm{No}$ & $-\mathrm{No}$ \\
\hline Panamá & $\begin{array}{l}\text {-Ley de } 20 \text { de febrero de } \\
1941 \text {-Ley de } 23 \text { de enero } \\
\text { de } 1957\end{array}$ & -No & -No \\
\hline
\end{tabular}

Fuente: Elaboración propia a partir de las leyes analizadas

Todas las leyes hacen alusión a la creación y funcionamiento de los AN. Pero a pesar de ello, tienen en cuenta algunos de los procesos técnicos archivísticos, tales como, la transferencia y expurgo; que por su notoriedad constituyen una actividad de primer orden y con incidencia directa en los demás archivos. A su vez, contemplan otros aspectos específico concernientes a los archiveros, su formación, las clases de 
archivo, etc. El cuadro 2 resume los principales aspectos que presentan cada una de las legislaciones archivísticas de los países centroamericanos.

\section{CUADRO 2}

PRINCIPALES ASPECTOS DE LAS LEYES

\begin{tabular}{|l||l||l||}
\hline \multicolumn{1}{|c|}{ PAÍS } & \multicolumn{1}{|c||}{ LEYES } & \multicolumn{1}{||}{ ASPECTOS } \\
\hline \hline Costa Rica & $\begin{array}{l}\text {-Ley 7202(24-10-92)* -Decreto } \\
\text { 24023-C (30-01-95)* }\end{array}$ & \multicolumn{1}{||}{} \\
\hline \hline Guatemala & -Decreto 1768 (25-06-68) & $\begin{array}{l}\text {-Reglamento de AGCA. Remisión } \\
\text { Exposiciones. }\end{array}$ \\
\hline \hline Nicaragua & -Decreto 401 (14-10-59) & -Función del AGN. Formación. \\
\hline \hline Panamá & -Ley de 20 de febrero de 1941 & -Función del AN. Transferencia. \\
\cline { 2 - 4 } & -Ley de 23 de enero de 1957 & $\begin{array}{l}\text {-Documento. Archivos estatales. Archivos } \\
\text { no estatales. Eliminación. Transferencia. } \\
\text { Archivero. Formación. }\end{array}$ \\
\hline
\end{tabular}

*Los principales aspectos de estas leyes serán puntualizados en la segunda parte.

Fuente: Elaboración propia a partir de las leyes analizadas

\subsection{AMÉRICA DEL SUR}

La última confluencia de la parte continental de América Latina y, por ende, del continente americano es América del Sur.

En la época colonial este territorio presentó la particularidad que estuvo bajo el dominio de España y Portugal. La primera, instituyó los Virreinatos de Nueva Granada, de Perú y del Río de la Plata. La segunda, instauró el Imperio de Brasil.

\subsubsection{LA LEGISLACIÓN ARCHIVÍSTICA EN ARGENTINA}

La legislación archivística de Argentina tiene sus cimientos en el período colonial, por cuanto los archivos creados bajo el dominio español en el Virreinato del Río de la Plata, fueron legislados y administrados según lo establecido por la Corona. Posterior a la independencia se continuó rigiendo bajo esas leyes; pero, la abrogación de las estructuras gubernamentales españolas y, en consecuencia, la formación de nuevas instituciones, demandaron la reordenación de los archivos y, por consiguiente, la creación de disposiciones legales para su organización. 
Bajo esta coyuntura, en 1821 fue emitido el decreto de creación del Archivo General de la Provincia del Buenos Aires. Posteriormente, el decreto del 29 de agosto de 1884 lo transformó en el AGN. En la segunda mitad del siglo XX se promulgó la ley 15930 de los Archivos de la República de Argentina, en vigencia actualmente.

\subsubsection{LEY 15930 ARCHIVO GENERAL DE LA NACIÓN}

La ley 15930 del Archivo General de la Nación, data de 10 de noviembre de 1961. Define a éste como el organismo que tiene por finalidad reunir, ordenar y conservar la documentación, para difundir las fuentes de la historia argentina.

La función cardinal del AGN es mantener y organizar la documentación pública, pero no estipula qué se entiende por ésta. No alcanza a definir satisfactoriamente que es documento público y menos aún el privado. Aunque apunta que estos últimos formarán parte del AGN cuando les fueran entregados para su custodia.

Uno de los aspectos que evidencia la obsolescencia de esta ley viene dado por art. 2, inc. B que dice: "se tiene que ordenar y clasificar con criterio histórico dicha documentación que está bajo su custodia"13. Privilegia la tradicional corriente historicista, que prevaleció por muchos años, en la organización de los archivos finales. Planteamiento totalmente alejado de los postulados de la teoría archivística moderna, pues la profesora Martín-Pozuelo Campillos señala que la validez de la clasificación archivística se concreta en el respeto total y absoluto a la génesis misma del documento o grupo de documentos generados por una institución ${ }^{14}$.

El AGN tiene cierta potestad sobre los demás archivos del país, tales como, encargarse de inspeccionar los archivos administrativos dependientes del poder ejecutivo y ejercer una especie de control sobre el funcionamiento de éstos. Anotan una serie de disposiciones relacionadas con la transferencia documental de los archivos centrales al AGN.

${ }^{13}$ Ibídem, pág. 22. 


\subsubsection{DECRETO 1571 TABLAS DE PLAZOS MÍNIMOS DE CONSERVACIÓN DE LOS DOCUMENTOS DE PERSONAL Y CONTROL}

El decreto 1571, de 9 de octubre de 1981, viene a llenar la carencia legal concerniente al expurgo de los documentos. Por lo tanto, su principal objetivo es planificar la valoración, selección y eliminación racional y sistemática de la documentación. Se fija para ello la elaboración de las "tablas de plazos mínimos de conservación de los documentos de personal y control"15, de aplicación obligatoria en toda la administración pública. El profesor Romero Tallafigo apunta que dichas tablas son una recopilación prospectiva a través del ciclo vital de las series documentales de una institución, a las que se le señala su condición de eliminable por un lado, o de conservable total o parcialmente, temporal o permanentemente, por otro lado, todo de acuerdo con la normativa vigente ${ }^{16}$.

El AGN es la autoridad competente para autorizar el expurgo, con miras a evitar la destrucción indiscriminada de documentos. Por medio de sendos anexos al decreto se incluye la metodología para ejecutar esa tarea y todo lo concerniente a la comisión de selección documental. La cual estará integrada por un abogado, un contador o licenciado en administración y un archivero. Es conveniente la incorporación de investigadores y usuarios, para obtener una argumentación más equilibrada al respecto.

\subsubsection{LA LEGISLACIÓN ARCHIVÍSTICA EN BOLIVIA}

La legislación archivística boliviana se remonta al siglo XIX, de esta época destaca la ley del 28 de noviembre de 1898 que dio origen al AGN. En la primera mitad del siglo XX merece la atención el decreto de 9 de mayo de 1940, que estableció la Dirección General de Bibliotecas, Archivos y Publicidad. La misión archivística consistió en la conservación del patrimonio documental y contribuir a la reorganización de los archivos de los tres poderes del Estado.

\footnotetext{
${ }^{14} \mathrm{M}^{\mathrm{a}} \mathrm{P}$. Martín-Pozuelo Campillos. La construcción teórica en Archivística: El principio de procedencia, 1996, pág. 57.

${ }^{15}$ En algunos países del área se conoce como tablas de plazos de conservación, tablas de expurgo, calendario de conservación, cuadro de expurgo, etc., pero su fin siempre es el mismo. Esto evidencia los problemas de terminología y la falta de normalización al respecto.

16M. Romero Tallafigo. Archivística y archivos. Soportes, edificios y organización, 1997, pág. 375.
} 


\subsubsection{DECRETO SUPREMO 22144}

El decreto supremo 22144, de 2 de marzo de 1989, declara de máxima utilidad y necesidad nacional toda la documentación pública, a razón de ser un recurso indispensable para la Administración, la investigación científica, la promoción de la conciencia cívica y el desarrollo nacional.

Queda claro la doble dimensión que tienen los documentos y -por ende- los archivos, a saber, administrativa y cultural. La primera, al servicio de las instituciones productoras, para gestionar y tramitar los asuntos propios de sus competencias. La segunda, enmarcada dentro de la dimanización cultural que debe ejercer todo archivo; tales como, facilitar la información para sustentar estudios retrospectivos de carácter científico o institucional, servicios educativos, visitas guiadas, exposiciones, etc.

Además se pronuncia sobre el ciclo vital de los documentos, denominado como documentación activa, documentación inactiva y documentación permanente, íntimamente relacionada con las etapas de archivo.

\subsubsection{DECRETO SUPREMO 22145}

El decreto supremo 22145, de 2 de marzo de 1989, declara de utilidad nacional la documentación inactiva perteneciente a la administración central, descentralizada, desconcentrada, local, judicial y universitaria.

$\mathrm{El}$ art. 2 define la documentación pública inactiva como: "Aquella que siendo producto o efecto de las funciones, actividades y trámites específicos de cualquier entidad pública, que habiendo estado en uso durante el lapso de su servicio activo, ingresa en receso y acaba retirada en depósitos dentro de la misma oficina de origen, fuera de ellas o en locales de su dependencia" ${ }^{17}$. Por lo tanto, los documentos inactivos son aquellos que han cumplido con el trámite o gestión inmediata que le dio origen, deben conservarse en los archivos centrales por un período determinado para su respectiva valoración.

${ }^{17}$ Archivum, 1995, pág. 72. 


\subsubsection{DECRETO SUPREMO 22146}

Continuando con el tema de la documentación inactiva, el decreto 22146, de 2 de marzo 1989, determina la necesidad de que ésta esté custodiada adecuadamente. Por lo tanto, le encomienda al Banco Central de Bolivia gestionar un repositorio especial para tales efectos, llevará el nombre de Repositorio Intermedio Nacional. Será un anexo del AGN y estará bajo su dirección, al respecto el art. 1 señala que: "Se encarga al Banco Central de Bolivia la gestión conducente al establecimiento de un repositorio especial donde se preserve y evalúe la destinación final de los documentos inactivos de las administraciones central y descentralizadas..."18.

Llama la atención el hecho de que una institución bancaria sea la encargada de la tramitación de las instalaciones de un archivo y de la contratación de sus recursos humanos. Lo más frecuente es que estas atribuciones recaigan en el Sistema Nacional de Archivos, cuando éste existe, o en un Ministerio como el de Cultura, Educación, o bien, en una entidad que tenga relación directamente con el entorno cultural. Es muy particular que una institución mercantil vele por el patrimonio documental de un país.

Este Repositorio viene hacer lo que se conoce como archivo intermedio, aunque en el decreto no queda señalado de esa manera, el origen de su creación y parte de sus funciones corresponden a éste. Por ejemplo, le atribuye la evaluación de la documentación para determinar su valor secundario, antes de ser transferido al AGN para su conservación definitiva. Tal como lo señala el art. 4: “...evaluar esos documentos, a fin que tienen un valor permanente para la información e investigación científica, la promoción de la conciencia cívica y el desarrollo nacional...a efectos de su conservación indefinida, en tanto, que las evaluadas como superflua sean desechadas bajo control legal"'19.

La conservación preventiva de los documentos está presente en este decreto. Recomienda para la construcción del edificio de archivo, se tengan en cuenta requisitos de absoluta seguridad contra todo riesgo causado por agentes destructivos físicos, químicos, biológicos, del medio ambiente, penetración clandestina y siniestros, entre otros.

\footnotetext{
18 Ibídem, pág. 74.

${ }^{19}$ Ibídem, pág. 74.
} 
Otro aspecto que contempla es la transferencia de la documentación inactiva de las entidades productoras al Repositorio Intermedio Nacional; queda establecido el procedimiento para su realización por medio del art. 14 que dice: "Se hará cada transferencia con sujeción a inventario elaborado por la respectiva entidad, en el que debe consignarse necesariamente la cuantía total de la documentación, apreciada en metros lineales" 20.

Por último, hace referencia a la valoración como el proceso archivístico que permite determinar los valores inherentes a los documentos; por su parte Pérez Herrero dice que la valoración consiste en el análisis y determinación de los valores (primario, secundario o vacío) de las series documentales, de sus plazos de transferencia, accesibilidad y oportunidad de conservación o eliminación ${ }^{21}$. Además, el art. 20 señala que dicha evaluación la realizará una comisión especializada, que tendrá por misión aprobar los criterios emitidos o sugerir las enmiendas pertinentes.

\subsubsection{LA LEGISLACIÓN ARCHIVÍSTICA EN BRASIL}

La legislación archivística brasileña data del siglo XIX, durante esta fase se promulgaron algunos decretos relacionados con el AN, tales como el 2541 de marzo de 1860 sobre su reorganización; el 6164 de 24 de marzo de 1876 referente a su reglamentación y el 1580 que fijó algunas modificaciones al anterior.

En el siglo XX se continuó propalando decretos atinentes al AN, por ejemplo, el 9197 de 9 de diciembre de 1911 que dictó un nuevo reglamento, a su vez, fue modificado por los decretos 16036 de 14 de mayo de 1923, 44862 de 21 de noviembre de 1958, 600-B de 5 de octubre de 1975 y por la portaria 173 de 8 de abril de 1992. En 1991 se emitió la ley 8159 , de 8 de enero de 1991, referente a los archivos públicos y privados. El SNA tiene sus cimientos en el decreto presidencial 83308 de 25 de setiembre de 1978; posteriormente reemplazado por el artículo 26 de la ley 8159 y el decreto 1173 de 29 de junio de 199422 .

\footnotetext{
${ }^{20}$ Ibídem, pág. 75.

${ }^{21}$ E. Pérez Herrero. El archivo y el archivero: sus técnicas y utilidad para el patrimonio documental canario, 1997, pág. 155.

${ }^{22} \mathrm{El}$ análisis de este decreto se realizará en la segunda parte.
} 


\subsubsection{LEY 8159 POLÍTICA NACIONAL DE ARQUIVOS PÚBLICOS E PRIVADOS E OUTRAS PROVIDÊNCIAS}

La ley 8159, de 8 de enero de 1991, dispone las políticas nacionales de los archivos públicos y privados. Señala que el Estado debe velar por la gestión y protección de los documentos de archivo, con el fin de que sirvan de instrumento para la administración, la cultura y el desenvolvimiento científico, como elemento de prueba e información.

Los archivos públicos son aquel conjunto de documentos producidos y recibidos -en el ejercicio de sus actividades- por órganos públicos del ámbito federal, estatal, del Distrito Federal y municipal, en concordancia con sus funciones administrativas, legislativas y judiciales.

Además, indica que los documentos públicos son identificados como "correntes, intermediários e permanentes"; denominación que corresponde al ciclo vital y en estrecha relación con las tres etapas del archivo, a saber, gestión, central y final.

En cuanto a los archivos privados, el Poder Público es el encargado de dictaminar cuáles de éstos son de interés público, social y, por lo tanto, relevantes para la historia y el desarrollo científico nacional. Éstos pueden ser donados a instituciones archivísticas públicas y su acceso se hará mediante autorización de sus propietarios.

\subsubsection{PORTARIA 173 REGIMENTO INTERNO DO ARQUIVO NACIONAL}

La portaria ministerial 173, de 8 de abril de 1992, establece el actual reglamento interno del AN. Las funciones que le atribuye son las convencionales de los de ésta etapa, a saber, recoger, custodiar y preservar el acervo archivístico del país.

El fin último de todo centro de información archivística es la accesibilidad a sus fuentes; como bien lo señala Pérez Herrero, ésta consiste en la posibilidad de consulta de los documentos depositados en los archivos, o al derecho de los ciudadanos a 
consultar el Patrimonio Documental, de acuerdo con la normativa vigente aplicable ${ }^{23}$. Aspecto que es tenido en cuenta en esta disposición, por cuanto estipula el acceso público a los datos que custodia el AN, por parte de los clientes externos, para la defensa de sus derechos y para la investigación, entre otros.

\subsubsection{LA LEGISLACIÓN ARCHIVÍSTICA EN COLOMBIA}

Durante la primera mitad del siglo $\mathrm{XX}$ fueron promulgadas varias leyes en materia archivística en este país de América del Sur, actualmente derogadas. En la segunda mitad de esa centuria se emitieron las que actualmente están rigiendo y que se exponen a continuación.

\subsubsection{LEY 80 CREACIÓN DEL ARCHIVO GENERAL DE LA NACIÓN}

La ley 80, de 22 de diciembre de 1989, dio origen al AGN. Entre sus funciones destaca la potestad de dirigir el SNA, con el fin de planear y coordinar la función archivística del país.

También le atribuye la responsabilidad de formular, orientar, coordinar y controlar las políticas nacionales en materia archivística; así como, promover la organización y fortalecimiento de los archivos del país y apoyar a los archivos privados, que custodien un fondo documental que revista especial importancia cultural e histórica.

Esta ley dispone unas funciones de avanzada para el AGN, más allá de las típicas de recoger, custodiar, etc. Están más enfocadas a la coordinación, control, dirección y apoyo, entre otras, propias del ente rector de un SNA.

${ }^{23}$ E. Pérez Herrero. Op. Cit., pág. 229. 


\subsubsection{DECRETO 1777 ESTATUTOS DEL ARCHIVO GENERAL DE LA NACIÓN}

El decreto 1777, de 3 de agosto de 1990, regula los estatutos relacionados con la organización y funcionamiento del AGN. También le asigna la responsabilidad de encargado de la planificación de las políticas archivísticas de Colombia. Además, ratifica la potestad de ente rector del SNA, con el fin de modernizar los archivos de la administración pública; cuya ley los concibe como centros de información, una concepción más moderna, integral y dinámica de éstos.

\subsubsection{LA LEGISLACIÓN ARCHIVÍSTICA EN CHILE}

Los antecedentes legales en materia archivística de Chile datan del siglo XIX. La ley de 17 de setiembre de 1847, dió origen a la Oficina de Estadística y el art. 2 contemplaba la fundación del AN. Éste era concebido como el responsable de la custodia de los documentos más importantes relativos a la legislación, al gobierno, a la administración de justicia y a los títulos de propiedad y familia de los ciudadanos, entre otros. Pero, a pesar de tan valiosos propósitos, no paso de ser más que una propuesta, pues la ley no se aplicó como tal y, por lo tanto, el archivo no fue creado.

En 1887 se produjo una reorganización de los ministerios del Estado, acorde con la nueva realidad política del país, en consecuencia la creación del Archivo General del Gobierno. Posteriormente, el decreto supremo 2811, de 30 de mayo de 1925, originó el Archivo Histórico Nacional; con el fin de reunir todos los documentos y manuscritos referentes a la historia chilena. Dos años después mediante la ley 7217, de 25 de noviembre de 1927, se fusionan estos dos archivos para dar paso a una sola institución con el nombre de AN.

\subsubsection{DECRETO 5200 CREACIÓN DE LA DIRECCIÓN GENERAL DE BIBLIOTECAS ARCHIVOS Y MUSEOS}

El decreto 5200, de 18 de noviembre de 1928, referente al origen de la Dirección General de Bibliotecas, Archivos y Museos, dictamina -en lo concerniente al 
AN- que su objetivo es reunir y conservar los archivos de los departamentos del Estado y los manuscritos relacionados con la historia nacional.

Por otra parte, determina los documentos que deberán ser transferidos al AN, así como los plazos de tiempo para la remisión. Está exento de este trámite el Ministerio de Relaciones Exteriores, por cuanto el decreto 210 de 1966 le atribuye conservar en su poder toda la información relacionada con los asuntos limítrofes. Además, el Ministerio de Defensa Nacional, por ley 18.771 de 1989, elimina y conserva su documentación y la de las Fuerzas Armadas y de Orden y Seguridad Pública.

\subsubsection{DECRETO SUPREMO 721 COMISIÓN DE SELECCIÓN DE DOCUMENTOS DE DESCARTE}

El decreto supremo 721, de 24 de enero de 1980, instituyó la Comisión de Selección de Documentos. Le atribuye la facultad de eliminar o desechar la documentación oficial antes de que ingrese al AN. Tiene la potestad de coordinar la eliminación de documentos y debe dejar constancia de ello.

\subsubsection{LA LEGISLACIÓN ARCHIVÍSTICA EN ECUADOR}

La legislación archivística ecuatoriana también tiene su origen en el siglo XIX. La ley de 24 de agosto de 1886, estableció la creación del Archivo del Poder Legislativo.

En el siglo XX el decreto de 19 de enero de 1938 dio origen al Archivo de Historia Nacional, hoy AN. Su reglamento interno viene dado por el decreto de 17 de mayo de 1938. Desde esa fecha hasta el presente se han promulgado otras leyes, pero la más significativa es la del SNA ${ }^{24}$, de 16 de junio de 1982.

\footnotetext{
${ }^{24}$ Esta ley será analizada en la segunda parte.
} 


\subsubsection{LA LEGISLACIÓN ARCHIVÍSTICA EN PARAGUAY}

La promulgación del decreto-ley 10756, de 28 de marzo de 1950, apunta sobre la creación de la Dirección General de Archivos, Bibliotecas y Museos de la Nación. En el mismo año sé público el decreto 12.789 que reglamenta la ley e indica las funciones del AN.

\subsubsection{LEY 1212 OBLIGATORIEDAD DEL DEPÓSITO DE LOS DOCUMENTOS OFICIALES EN EL ARCHIVO GENERAL DE LA NACIÓN}

La ley 1212 de 1986, sobre la obligatoriedad del depósito de los documentos oficiales en el AGN, argumenta que las instituciones y organismos del Estado centralizado y descentralizado tienen la obligación de conservar, en sus respectivos archivos, la documentación por 15 años. Al respecto, el art. 2 dispone que: "Las instituciones y organismos entregarán al Archivo General de la Nación, para custodia, conservación y catalogación, la parte de sus respectivos archivos que no estuvieren en uso..." 25 .

Los bienes del Patrimonio Nacional son todos aquellos escritos, mapas, planos, esquemas, fotografías, dibujos, documentos y, en general, todo elemento probatorio de actuación realizados por las respectivas instituciones.

La ley presenta cierta ambigüedad respecto a las políticas de expurgo, únicamente plantea que el director del AGN y el principal responsable de cada institución u organismo, determinarán conjuntamente que documentos ameritan ser conservados en esta entidad. No señala cuáles son los procedimientos a seguir para efectuar esa actividad. Además es imprescindible -y no lo considera- tener en cuenta los criterios de otros profesionales como juristas, administrativistas, archiveros y usuarios para realizar la valoración.

Por lo anterior, es necesario la creación de una comisión interdisciplinar de evaluación para precisar la vigencia administrativa o permanente de la documentación;

${ }^{25}$ Archivum, 1996, pág. 81. 
Vázquez Murillo indica que la comisión evaluadora es un equipo de expertos que, coordinado por el archivero, evalúa los documentos de archivo a fin de determinar el plazo de su retención (luego de agotada su vigencia) y su destino final. ${ }^{26}$

El acceso a la información que custodia un archivo es su misión de mayor envergadura. La legislación señala que los documentos son facilitados al público para efectos de investigación o como medio de extensión cultural, salvo aquellos que por su naturaleza han sido declarados reservados. Al respecto el art. 4 dice: "Los documentos en poder del Archivo General de la Nación quedan librado al público, sea para la tarea de investigación o como medio de difusión cultural, salvo aquellos declarado como reservados por sus naturaleza. El acceso a estos documentos queda librado a una autorización especial del Director del Archivo General de la Nación”27.

\subsubsection{LA LEGISLACIÓN ARCHIVÍSTICA EN PERÚ}

Los antecedentes legislativos del entorno archivístico peruano tienen su origen en el siglo XIX. El 15 de mayo de 1861 fue creado el AN, cuyo principal objetivo era centralizar los documentos históricos y oficiales de la Nación.

La ley 4666, de 15 de mayo de 1923, apunta sobre la reorganización de AN, dividida en secciones de documentos históricos y administrativos, de procesos judicial y de instrumentos notariales. El 26 de abril de 1924 promulgaron los reglamentos del AN y el de la Junta Económica del Archivo Nacional.

En la década de los 70 sobresale el decreto-ley 19414 de la defensa, conservación e incremento del Patrimonio Documental y el decreto supremo 022-75-ED que reglamenta la Ley. En los 80 surgen una serie de leyes vinculadas con el AGN, le adjudican funciones de mayor amplitud y responsabilidad. Destaca la ley 20 orgánica del AGN, que la convierte en organismo público descentralizado, dándole un lugar preferente como conductor de los archivos de Perú.

\footnotetext{
${ }^{26}$ M. Vázquez Murillo. Manual de selección documental, 1995, pág. 133.

${ }^{27}$ Archivum, 1996, pág. 81.
} 
La década de los 90 es muy significativa para la archivística peruana porque se aprobó la ley 25323 del SNA y el decreto supremo 008-92 JUS que lo reglamenta y las resoluciones ministeriales 201.1 sobre la estructura orgánica y funciones del AGN.

\subsubsection{RESOLUCIÓN MINISTERIAL 201.1 ESTRUCTURA ORGÁNICA Y FUNCIONES DEL ARCHIVO GENERAL DE LA NACIÓN}

La resolución ministerial 201.1, de 31 de marzo de 1992, es el instrumento normativo que fija y regula la estructura orgánica y las funciones del AGN.

El AGN es una institución pública descentralizada y el órgano rector y central del SNA. Tiene una serie de fines muy concretos, de los cuales destaca ser el comisionado para proponer las políticas nacionales en materia archivística, así como, supervisar y evaluar su cumplimiento. Además, le atribuye la responsabilidad de normalizar y racionalizar la producción administrativa y la eliminación de documentos de la administración pública.

Respecto a los objetivos más significativos que le confiere la ley destacamos los siguientes:

- Organizar técnicamente el PDN.

- Identificar el desarrollo armónico de los componentes del SNA.

- Fomentar y difundir el uso de los archivos, facilitando su accesibilidad y servicio.

- Contribuir a la formación integral y reconocimiento profesional del personal de los archivos.

Es gratificante el hecho de que esta ley manifiesta la preocupación por la instrucción de los archiveros, que éstos tengan un estatus decoroso y que su labor sea reconocida como cualquier otra profesión. 
En cuanto a las funciones más representativas predominan las siguientes:

- La formulación y emisión de normas técnicas para la organización y funcionamiento de los archivos públicos, regionales y locales.

- Calificar, acopiar, conservar, organizar, describir y servir la documentación histórica.

- Promover y apoyar a los organismos del Estado y entidades privadas que soliciten programas de formación.

- Capacitación del personal especializado.

- Impulsar la investigación archivística.

El AGN cuenta con tres órganos de línea, comisionados para la investigación y normalización en materia archivística, que son los siguientes:

a- La Dirección Nacional de Desarrollo de Archivos: Órgano encargado de orientar, proponer y conducir las acciones de normatividad, investigación y desarrollo de tecnología en el campo de los archivos.

Un aspecto digno de resaltar es la importancia que se le da a la investigación, pues ésta es una actividad tan necesaria para el fortalecimiento, enriquecimiento y difusión de la Archivística.

b- La Dirección Nacional del Archivo Intermedio: Dependencia comisionada de supervisar y asesorar la organización y funcionamiento de los archivos públicos, así como, efectuar el seguimiento de la aplicación de las normas admitidas por el SNA. Además le corresponde acopiar, sistematizar, custodiar y poner al servicio de los usuarios la documentación proveniente de los archivos públicos. Por último, evaluar y transferir la documentación al Archivo Histórico dentro de los plazos de ley.

c- La Dirección Nacional de Archivo Histórico: Organismo responsable de la conservación y aplicación de los procesos técnicos archivístico de la documentación de 
valor permanente, con el fin de ponerla al servicio de los clientes para efectos de información, difusión cultural, investigación científica, programas educativos y de prueba jurídica; entre otros.

\subsubsection{LA LEGISLACIÓN ARCHIVÍSTICA EN URUGUAY}

Las referencias que tenemos sobre la legislación uruguaya son muy exiguas. Únicamente podemos anotar que el decreto de 5 de marzo de 1827 creó el Archivo General de la Nación de la República Oriental del Uruguay. Posteriormente cambió de nombre y pasó a llamarse Archivo General de la Administración y en 1926 adquiere su actual denominación, AGN.

\subsubsection{DECRETO DE 1977 REGLAMENTO ORGÁNICO, NORMAS SOBRE ADMINISTRACIÓN DOCUMENTAL Y DISPOSICIONES GENERALES}

Por decreto del Poder Ejecutivo de 1977, fue aprobado el Reglamento Orgánico, Normas sobre Administración Documental y Disposiciones Generales. Establece que el AGN dependerá orgánicamente del Ministerio de Educación y Cultura, tendrá como misión la custodia y conservación de la documentación pública del país.

De sus postulados sobresale lo concerniente a las transferencias documentales, pero únicamente especifica los plazos para su ejecución. Por su parte, se exceptúa de este trámite a los expedientes relativos a asociaciones civiles y fundaciones $\mathrm{y}$, en general, los que fueran necesarios para el ejercicio de las funciones de la policía.

\subsubsection{LA LEGISLACIÓN ARCHIVÍSTICA EN VENEZUELA}

Lo único que podemos decir respecto a la legislación archivística de este país de América del Sur, es que el 23 de marzo de 1914 se aprobó el reglamento provisional del AN. El 20 de julio de 1926 fue promulgado el reglamento del AN y el 26 de junio de 1945 la ley de Archivos Nacionales. 


\subsubsection{LEY DE 26 DE JUNIO DE 1945 ARCHIVOS NACIONALES}

El 26 de junio de 1945 se emitió la ley de Archivos Nacionales, establece que el Estado venezolano velará por la organización de todos los archivos del país, por medio de los organismos y funcionarios competentes.

La transferencia de documentos es señalada de forma suscita, indica que el Ejecutivo Federal podrá disponer, cuando lo creyera conveniente, el traslado al AN; tales como los expedientes concluidos que se hallen en los archivos parciales de los departamentos ejecutivos, en las oficinas del Poder Judicial y en las demás oficinas de carácter nacional. Más no regula el procedimiento a seguir para realizar ésta actividad, ni el establecimiento de los plazos de retención.

\subsubsection{ANÁLISIS COMPARATIVO}

En América del Sur existe una amplia diversidad de leyes en materia archivística. De los diez países en estudio seis poseen disposiciones relacionadas con los AN o AGN, seis de ellos hacen mención a leyes de carácter específico y cuatro a los SNA.

Un dato interesante es que algunos países tienen más de una ley, como Perú, Brasil, Colombia, Bolivia, Argentina y Chile. A su vez, existen casos que dentro de una misma categoría de legislación se han promulgado más de una ley; por ejemplo, Bolivia tiene tres leyes de carácter específico, Colombia dos sobre el AGN y Perú tres sobre el SNA. Por su parte, Brasil es el único país que cuenta con todos los tipos de leyes que se determinaron para realizar de este trabajo.

En otro orden de cosas, estas leyes presentan la particularidad que a pesar de la antigüedad, de muchas de ellas, aún continúan vigente; lo cual presenta problemas de obsolescencia en cuanto a los planteamientos de los procesos técnicos archivísticos y no responden a la realidad presente.

El cuadro 3 presenta la relación de los países del Sur que tienen legislación concerniente al universo de los archivos. 
CUADRO 3

LEGISLACIONES DE LOS PAÍSES DE AMÉRICA DEL SUR

\begin{tabular}{|c|c|c|c|}
\hline PAÍS & LEY DE AN O AGN & LEYES DE CARÁCTER ESPECÍFICO & LEY DE SNA \\
\hline Argentina & -Ley $15930(10-11-61)$ & -Decreto 1571. Referente al expurgo (09-10-81) & -No \\
\hline Bolivia & $-\mathrm{No}$ & $\begin{array}{l}\text {-Decreto Supremo 22144. Referente a } \\
\text { documentación pública }(02-03-89) \\
\text {-Decreto Supremo 22145. Concerniente a la } \\
\text { documentación inactiva (02-03-89) } \\
\text {-Decreto supremo 22146. Sobre al Repositorio } \\
\text { intermedio Nacional (02-03-89) }\end{array}$ & $-\mathrm{No}$ \\
\hline Brasil & $\begin{array}{lll}- \text { Portaria } & 173 \quad(08-04- \\
92) & & \\
\end{array}$ & $\begin{array}{l}\text {-Ley } 8159 . \quad \text { Relacionado con los archivos } \\
\text { públicos y privados }(08-01-91)\end{array}$ & \begin{tabular}{|l}
-Decreto No 1173 \\
$(29-06-94)$
\end{tabular} \\
\hline Colombia & $\begin{array}{l}\text {-Ley } 80(22-12-89) \\
\text { Decreto } 1777(03-08-90)\end{array}$ & $-\mathrm{No}$ & \begin{tabular}{|ll}
- Acuerdo 07 \\
06-94)
\end{tabular} \\
\hline Chile & $\begin{array}{l}- \text {-Decreto } 5200 \quad(18-11- \\
28)\end{array}$ & $\begin{array}{l}\text {-Decreto Supremo } 721 . \quad \text { Concerniente a la } \\
\text { comisión de selección documental (24-01-80) }\end{array}$ & $-\mathrm{No}$ \\
\hline Ecuador & -No & -No & $\begin{array}{l}\text {-Ley de } 15 \text { de junio } \\
\text { de } 1982\end{array}$ \\
\hline Paraguay & $-\mathrm{No}$ & $\begin{array}{l}\text {-Ley 1212. Obligatoriedad del depósito de los } \\
\text { documentos oficiales en el Archivo General de } \\
\text { la Nación. (1986) }\end{array}$ & -No \\
\hline Perú & $\begin{array}{l}\text {-Resolución Ministerial } \\
201.1(31-03-92)\end{array}$ & $-\mathrm{No}$ & \begin{tabular}{|l|}
-Ley 25323 \\
$(10-06-91)$ \\
-Decreto Supremo \\
008-92-JUS \\
$(26-06-92)$ \\
-Resolución \\
Jefatural 073-85- \\
AGN-J (31-05-95)
\end{tabular} \\
\hline Uruguay & $-\mathrm{No}$ & $\begin{array}{l}\text {-Decreto de } 1977 . \quad \text { Reglamento orgánico, } \\
\text { normas sobre administración documental y } \\
\text { disposiciones generales. }\end{array}$ & $-\mathrm{No}$ \\
\hline Venezuela & $\begin{array}{l}\text {-Ley de } 26 \text { de junio de } \\
1940\end{array}$ & & \\
\hline
\end{tabular}

Fuente: Elaboración propia a partir de las leyes analizadas.

Es evidente el marcado interés y preocupación por la reunión de toda la documentación, en sus diversas fases, en los archivos respectivos; así como, el tratamiento técnico al problema que presenta la explosión documental. Las leyes manifiestan planteamientos muy variopintos, de los cuales son comunes a la mayoría de ellas lo relacionado con la transferencia y el expurgo. A su vez, éstos tienen un radio de acción de mayor alcance, ya que su aplicación afecta a todos los archivos.

También las leyes contemplan otros aspectos en estrecha relación con las demás actividades del quehacer archivístico, tales como la conservación, organización y el acceso, etc. Así como otras más específicas, vinculados con la formación, las clases de archivo, la difusión, etc. Por último, los preceptos legales atinentes a los AN o AGN, 
hacen mención a las funciones o atribuciones de estos archivos y, en algunos casos, a los asuntos supracitados. El cuadro 4 recapitula los principales aspectos que contemplan las leyes.

\section{CUADRO 4}

PRINCIPALES ASPECTOS DE LAS LEYES

\begin{tabular}{|c|c|c|}
\hline PAÍS & LEYES & ASPECTOS \\
\hline \multirow[t]{2}{*}{ Argentina } & -Ley 15930 (10-11-61) & $\begin{array}{lccc}\text {-Atribuciones del AGN. } & \text { Difusión. } \\
\text { Organización. Archivo Central. } & \end{array}$ \\
\hline & -Ley $1571(09-10-81)$ & -Expurgo. \\
\hline \multirow[t]{3}{*}{ Bolivia } & -Decreto Supremo 22144 (02-03-89) & -Documentación. \\
\hline & -Decreto Supremo 22145 (02-03-89) & -Documentación inactiva. \\
\hline & -Decreto Supremo 22146 (02-03-89) & $\begin{array}{lcc}\text {-Repositorio } & \text { Intermedio } & \text { Nacional. } \\
\text { Conservación. Transferencia. } & \\
\end{array}$ \\
\hline \multirow[t]{3}{*}{ Brasil } & -Portaria 173 (08-04-92) & \multirow{3}{*}{$\begin{array}{l}\text {-Funciones del AN. Acceso. } \\
\text { Documentación. } \\
\text {-Archivos públicos y privados. }\end{array}$} \\
\hline & - - Ley $\quad 8159$ & \\
\hline & 91) & \\
\hline \multirow[t]{3}{*}{ Colombia } & -Ley 80 (22-12-89) & -Funciones del AGN. \\
\hline & -Decreto 1777 (03-08-90) & -Funciones del AGN. Formación. \\
\hline & -Acuerdo $07^{*}(29-06-94)$ & \\
\hline \multirow[t]{2}{*}{ Chile } & -Decreto $\quad 5200$ & -Objetivos del AN. Transferencia. \\
\hline & -Decreto Supremo 721 (24-01-80) & -Comisión de Selección Documento. \\
\hline Ecuador & -Ley de 16 de junio de $1982 *(15-06-82)$ & \\
\hline Paraguay & -Ley 1212 (1986) & -Custodia de documentos. Expurgo. \\
\hline \multirow[t]{4}{*}{ Perú } & $\begin{array}{l}\text {-Resolución Ministerial } 201.1 \\
(31-03-92)\end{array}$ & -Funciones y objetivos AGN. Formación. \\
\hline & -Ley 25323* (10-06-91) & \\
\hline & -Resolución 073-85 AGN-J* (31-05-95) & \\
\hline & $\begin{array}{l}\text {-Decreto Supremo 008-92 JUS* } \\
(26-06-92)\end{array}$ & \\
\hline Uruguay & -Decreto de 1997 & $\begin{array}{l}\text {-Administración de documento. } \\
\text { Transferencia. }\end{array}$ \\
\hline Venezuela & Ley de 26 de junio de 1940 & -Transferencia. Formación. \\
\hline
\end{tabular}

*Los principales aspectos de estas leyes serán puntualizados en la segunda parte.

Fuente: Elaboración propia a partir de las leyes analizadas

\subsection{LAS ANTILLAS}


La región de las Antillas, también conocida como el Caribe, está constituida por una serie de naciones independientes y de algunas islas que aún forman parte de países europeos (Inglaterra, Francia y Holanda) o de Estados Unidos.

El Caribe se ha caracterizado por ser una zona de tránsito, de enlace y comunicación. Hoy día se ha constituido en una región trascendental, por donde transcurren importantes vías marítimas, rutas aéreas y comerciales; vitales, no sólo para los estados caribeños, sino también a escala mundial.

\subsubsection{LA LEGISLACIÓN ARCHIVÍSTICA EN CUBA}

En el siglo XIX se emitió la Real Orden 531, de 28 de enero de 1840, que estableció la unión de los archivos de la Primera Secretaría de la Capitanía General, el de Intendencia del Ejército y Real Hacienda, el del Real Consulado de Agricultura, Industria y Comercio y el de la Junta de Fomento de la Habana.

Esa fusión dio origen, años después, al Archivo General de la Real Hacienda de la Isla, hoy día AN. Cuya misión, plantea Solavarría, es la de promover el desarrollo integral de los archivos y procurar la modernización de la función archivística en todo el país, al impulsar su desarrollo hacia el logro de principios y técnicas modernas para la administración de documentos, a partir de sus propias experiencias y las obtenidas a través de otras instituciones homólogas; la de capacitar al personal que labora o debe laborar en los archivos; la de dirigir las investigaciones archivísticas y la de autorizar -a través de la Comisión Nacional de Control y Peritaje- la depuración de la documentación, como garantía para la salvaguarda del patrimonio documental ${ }^{28}$.

\subsubsection{LEY 714 ARCHIVO NACIONAL}

Los archivos cubanos están regulados por la ley 714 de 1960. Aunque no existe un SNA, el AN ejerce la función de órgano rector de las políticas archivísticas de la Isla.

La transferencia documental es contemplada en ésta ley y obliga a todas las dependencias de los tres poderes del Estado, así como, a los organismos paraestatales y

${ }^{28}$ B. Solavarría. El oficio de la transparencia, 1977, pág. 43. 
autónomos a remitir la documentación -que custodian en los archivos de sus entidadesal AN.

Por otra parte, el director del AN está facultado como máxima autoridad para ordenar la eliminación de documentos de la administración pública, a tenor de lo que establece el art. 32: "Se faculta al Director del Archivo Nacional como única autoridad capaz de ordenar la destrucción de documentos de la administración pública del Estado en sus tres poderes y organismos paraestatales. Se llevará un Libro Especial de Documentación Destruida en el Archivo Nacional"29.

Podemos calificar esta disposición de centralista, en tanto, responsabiliza sólo a una persona para emitir criterios sobre una actividad tan delicada como el expurgo. Para llegar a dicha determinación lo más conveniente es que la realice una comisión de expertos, que pronuncie diversos juicios para llegar a un acuerdo en común. El profesor Cruz Mundet señala que dicha comisión se constituye como un grupo de estudio del que forman parte representantes de la entidad que ha generado los documentos, administrativistas, investigadores y archiveros. Al estar presentes todos lo grupos interesados en el proceso documental: creadores, juristas, usuarios y gestores, que representan el abanico más amplio de puntos de vista, se obtienen las máximas garantías de que el resultado se acerque al ideal objetivo en la medida de lo posible ${ }^{30}$.

\subsubsection{LA LEGISLACIÓN ARCHIVÍSTICA EN PUERTO RICO}

La legislación archivística puertorriqueña está compuesta por la ley 5 , de 8 de diciembre de 1955, sobre la Administración de Documentos Públicos y el Reglamento 4284, de 19 de julio de 1990, también sobre la Administración de Documentos Públicos ${ }^{31}$. La ley dio origen al Archivo General de Puerto Rico y fija sus funciones.

\subsubsection{LEY 5 ADMINISTRACIÓN DE DOCUMENTOS PÚBLICOS}

\footnotetext{
${ }^{29}$ Archivum, 1995, pág. 150.

30J. R. Cruz Mundet. Op. Cit., pág. 212.

${ }^{31}$ Las gestiones para conseguir este reglamento fueron infructuosas, por lo que únicamente podemos dejar constancia de su existencia.
} 
La ley 5, de 8 de diciembre de 1955, sobre la Administración de Documentos Públicos, fue enmendada el 13 de junio de 1960 y el 4 de junio de 1979. Esta ley tiene como objetivo establecer un programa sistemático de conservación de documentos que, en consideración a su valor histórico, legal, administrativo o informativo, merecen preservarse; en consecuencia, eliminar aquellos que carecen de valor permanente y que han perdido su utilidad o vigencia administrativa.

El Archivo General del Estado Libre y Asociado de Puerto Rico es el depositario oficial de toda la documentación pública y privada a él transferida. Además, estará dirigido por un archivero, que será el responsable de la custodia, conservación y uso de la documentación.

La ley establece que el archivo debe contar con los recursos necesarios para la preservación de los documentos por medio de métodos modernos. También contempla la preparación de guías y otros instrumentos descriptivos necesarios a fin de localizar la información. Así como, la reproducción, publicación y exposición de documentos que así lo ameriten.

\subsubsection{LA LEGISLACIÓN ARCHIVÍSTICA EN REPÚBLICA DOMINICANA}

La legislación archivística de este país antillano viene dada por la ley de Organización del Archivo General de la Nación, el reglamento de ésta, la ley de Documentos Nacionales, la ley de 1964 que exceptúa a los archivos del pago de impuestos sucesoral y la ley de 1968 sobre Patrimonio Cultural de la Nación.

\subsubsection{LEY 1085 ORGANIZACIÓN ARCHIVO GENERAL DE LA NACIÓN}

El 6 de abril de 1936 se emitió la ley 1085 sobre la Organización del Archivo General de la Nación. Establece que éste tendrá a su cargo la conservación de los documentos que procedan de los archivos, de las diversas oficinas y dependencia del 
Estado, que tengan interés histórico. El Poder Ejecutivo es el responsable de determinar, en cada caso, cuando deben ser depositados en él.

\subsubsection{REGLAMENTO 1590 BIS ORGANIZACIÓN DEL ARCHIVO GENERAL DE LA NACIÓN}

Como señalamos en párrafos anteriores, el proceso archivístico de remisión de documentos consiste en traspasar los fondos de un archivo a otro, es decir, de gestión a central, de central a intermedio y de intermedio a histórico. Por su parte, las archiveras Molina y Leyva argumentan que la transferencia es el procedimiento habitual de ingreso de fondos en un archivo, mediante traslado de las fracciones de series documentales, una vez que éstas han cumplido el plazo de permanencia en la etapa anterior dentro de la red de archivos en la que esté integrado ${ }^{32}$. Ahora bien, para ejecutar ese proceso es imprescindible dejar constancia de lo que se envía y recibe, para tal efecto se debe elaborar y cumplimentar las listas de remisión o relación de entrega.

Por lo anterior, en el reglamento 1590 -de 30 de mayo de 1936- que regula la ley 1085, dispone las pautas para realizar las transferencias de documentos de las oficinas publicas al AGN. Su procedimiento viene dado por el art. 1 que dice: "Las oficinas públicas, al hacer el envío de documentos al Archivo General de la Nación, formularán un inventario de los mismos, en triplicado, en el que se consignará el número de legajos depositado, los expedientes de que conste cada legajo y el número de documentos de que consta cada expediente"33.

A pesar de lo antiguo del reglamento, presenta unas disposiciones interesantes, por cuanto considera ineludible respetar el principio de procedencia y el de orden natural de los documentos, para realizar la clasificación; la profesora Martín-Pozuelo Campillos señala que dicho principio se enuncia como el respeto a la procedencia de los fondos y se define archivísticamente como la necesaria obligatoriedad de no mezclar en un mismo archivo la documentación procedente de diferentes fondos. Más claramente,

\footnotetext{
32J. Molina Nortes y V. Leyva Palma. Técnica de archivo y tratamiento de la documentación administrativa, 1996, pág. 141.

${ }^{33}$ Revista del SED, 1997, pág. 91.
} 
la obligatoriedad de que la documentación de un fondo bajo ningún concepto se vea mezclado con la de otro ${ }^{34}$.

En cuanto a la ordenación, establece que no deben deshacerse las series que constituyen un expediente, por lo cual es imprescindible conservar el orden original.

\subsubsection{ANÁLISIS COMPARATIVO}

De los tres países de las Antillas que poseen legislaciones archivísticas -según las fuentes consultada- sólo dos de ellos, Cuba y República Dominicana, corresponden a los AN. Por su parte, Puerto Rico es el único que tiene ley de carácter específico, pero presenta la particularidad que hace mención al AN. Más ninguno de los tres tiene SNA.

El cuadro 5 contempla los países caribeños que cumplen con los criterios para el estudio de las leyes.

\section{CUADRO 5}

LA LEGISLACIÓN ARCHIVÍSTICA DE LOS PAÍSES DE LA ANTILLAS

\begin{tabular}{|c|c|c|c|}
\hline PAÍS & LEY DE AN O AGN & $\begin{array}{l}\text { LEYES DE CARÁCTER } \\
\text { ESPECÍFICO }\end{array}$ & LEY DE SNA \\
\hline Cuba & -Ley $714(1960)$ & -No & -No \\
\hline Puerto Rico & -No & \begin{tabular}{|l}
-Ley 5. Administración de \\
documentos $(08-12-55)$
\end{tabular} & $-\mathrm{No}$ \\
\hline $\begin{array}{l}\text { República } \\
\text { Dominicana }\end{array}$ & $\begin{array}{l}\text {-Ley } 1085(06-04-36) \\
\text {-Reglamento } 1590 \mathrm{Bis} \\
(30-05-36)\end{array}$ & -No & $-\mathrm{No}$ \\
\hline
\end{tabular}

Fuente: Elaboración propia a partir de las leyes analizadas.

La transferencia de documentos es la actividad común que regulan la mayoría de las leyes. También tienen en cuenta otros procesos como el expurgo, la conservación y la organización. Por su parte, Cuba hace referencia a otros aspectos más concretos como la formación y Puerto Rico a la difusión. El cuadro 6 recoge los principales aspectos que contemplan estas leyes.

\section{CUADRO 6}

PRINCIPALES ASPECTOS DE LAS LEYES

${ }^{34}$ M. P. Martín-Pozuelo Campillos. Op. Cit., pág. 129. 


\begin{tabular}{|c|c|c|}
\hline PAÍ́S & LEYES & ASPECTOS \\
\hline Cuba & -Ley 714 & $\begin{array}{l}\text {-Funcionamiento del AN. } \\
\text { Transferencia. Eliminación. } \\
\text { Formación. }\end{array}$ \\
\hline Puerto Rico & -Ley 5 & $\begin{array}{lr}\text {-Documento } & \text { público. } \\
\text { Conservación. } & \text { Difusión. } \\
\text { Archivero } & \\
\end{array}$ \\
\hline \multirow[t]{2}{*}{ República Dominicana } & -Ley 1085 & -Organización del AGN \\
\hline & -Reglamento 1590 BIS & $\begin{array}{l}\text {-Transferencia. } \\
\text { Organización }\end{array}$ \\
\hline
\end{tabular}

Fuente: Elaboración propia a partir de las leyes analizadas.

\section{3- SEGUNDA PARTE: LAS LEYES DE LOS SISTEMAS NACIONALES DE ARCHIVOS}

Las transformaciones tan aceleradas que está viviendo la sociedad apuntan a que cada vez se agrupen esfuerzos para lograr objetivos y metas comunes. La integración de diversos sectores, por ejemplo el económico, conlleva a una reducción de costes y a proponer mejores planteamientos estratégicos y de proyección; de cara a brindar un eficiente y eficaz servicio para obtener prósperos resultados.

Actualmente, la cohesión parece ser el elemento clave para lograr el éxito en cualquier campo; situación que también repercute en los centros de información archivística y, por ende, en los archivos. Ninguno de ellos puede, ni debe, trabajar de forma aislada, todo lo contrario, tienen que buscar los mecanismos más adecuados para actuar en conjunto. Así poder detectar problemas o limitaciones comunes y buscar una solución providencial para todos, que favorezca la atención y el uso racional de los servicios y recursos. Situación factible de lograr con la unión de todos los archivos mediante un sistema nacional, con un ente dirigente con capacidad de liderazgo.

La oportuna conveniencia y necesidad de administrar, coordinar, asesorar y supervisar todos los archivos de una nación, es lo que da origen a los SNA; Mejía lo define como el conjunto de los archivos públicos y privados existentes en el país, 
vinculados $\mathrm{y}$ articulados en forma tal que sus recursos $\mathrm{y}$ servicios puedan ser aprovechados por la comunidad ${ }^{35}$. Lo cual conlleva a la obligación de proteger y difundir el patrimonio documental y hacer efectivo el derecho a la información por parte de los ciudadanos.

Un SNA tiene que tener como atribuciones planificar, dirigir, coordinar, asesorar, dinamizar, difundir y controlar los archivos que lo componen. Para convertirlos en fuentes potenciales de información del presente y del pasado, al servicio de la entidad productora, los investigadores y el público en general.

Además, debe ser atractivo y ofrecer elementos de estímulo y escrupulosidad para aquellos archivos que por su naturaleza no forman parte obligada del sistema, tales como, los privados, familiares y personales. Su incorporación depende de su libre y espontánea decisión.

De la revisión bibliográfica podemos concluir que en la configuración de un SNA es necesario tener en cuenta tres elementos básicos: los aspectos que normalizan el sistema, un ente coordinador o rector que lo dirija y una ley que lo regule.

Respecto al primero, es conveniente que contemple un conjunto de elementos generales que estructuren el SNA, es decir, que sirvan de armazón y que a partir de ellos se construyan una serie de complementos que darán cuerpo o forma al Sistema; entre ellos podemos citar los siguientes:

-Definición del Sistema.

-Objetivos, misión y funciones.

-Órgano rector del Sistema.

-Archivos que lo integran y su alcance.

-La existencia y atribuciones de las diversos etapas del archivo (gestión, central, intermedio y final).

-Normalización de los procesos técnicos archivísticos.

-Acceso a la información.

-Los archiveros como profesionales de los archivos.

-Formación de los archiveros.

35M. Mejía. Memorias de lo visible, 1997, pág. 28. 
-Políticas culturales y de difusión de los archivos.

-Los archivos privados, familiares y personales, entre otros.

-Reproducción de la información.

-Las tecnologías de la información y comunicación.

-Los documentos electrónicos.

-La formación de usuarios.

-Sanciones por incumpliendo a la ley.

En cuanto al segundo elemento, el ente rector, el SNA debe tener una autoridad central o ente rector que planifique, dirija, controle y evalúe las políticas archivísticas. En los países de América Latina, que tienen SNA, la responsabilidad de dirigirlo ha recaído en los AN o AGN, por su importancia, prestigio, experiencia y posición dentro del conjunto archivístico institucional.

Si se sigue esa misma línea en aquellos países que no tengan Sistema y que lo vayan a integrar; es preciso reforzar en toda su extensión a estos archivos. Dotarlos de infraestructura, recursos humanos, recursos económicos y recursos materiales, entre otros, para tan importante misión. Además, Mejía señala que deberá tener un alto nivel de excelencia y creatividad para que se reconozca y pueda ejercer de manera natural su autoridad y liderazgo ${ }^{36}$.

El ente rector de SNA, sea cual fuese, tiene que tener excelentes relaciones con las demás instituciones estatales y, por qué no, con las privadas; amén de que le tengan en cuenta dentro de las políticas nacional de desarrollo. Todo esto dependerá -en gran parte- de la gestión que realice, de la imagen que proyecte y de la credibilidad de sus planteamientos; así como, del apoyo de todos sus miembros, de la comunidad archivística en general y, sobre todo, de los gobernantes.

Es conveniente que la ubicación jerárquica del SNA y, por ende, su ente rector esté adscrita a una institución de alto rango dentro de la administración pública; a su vez, que le permita una autonomía administrativa y financiera para facilitar su gestión.

El tercer elemento, es la necesidad de que el SNA esté dotado de un marco jurídico que lo respalde y ordene la puesta en marcha de sus planteamientos. No es que la legislación sea la panacea para que el Sistema funcione de forma óptima, pero 
constituye la base legal imprescindible para definir líneas de actuación, que establezca su existencia y regule su funcionamiento. A esto habría que agregarle otro elemento fundamental, el apoyo y decisión política de los gobernantes de turno, para hacer efectivo -en todos sus aspectos- el cumplimento de la ley.

Los aspectos que se consideraron para determinar los SNA en el área geográfica en estudio, fue su establecimiento de hecho y de derecho, es decir, que tuvieran un corpus legal que promulgue su existencia, de la cual se dicten directrices para todo el ámbito archivístico nacional. Dichos requerimientos los reúnen únicamente cinco países de la parte continental, que son: Brasil, Colombia, Costa Rica, Ecuador y Perú.

\subsection{EL SISTEMA NACIONAL DE ARCHIVOS DE BRASIL}

El origen del SNA de Brasil se remonta al año de 1978, cuando se dictó el decreto 82308 que creó el Institui o Sistema Nacional de Arquivos, posteriormente fue derogado en 1994. Luego, el 29 de junio de 1994, se promulgó el decreto 1773 que dispone la organización, competencias y funcionamiento del Conselho Nacional de Arquivos (CNA) e o Sistema Nacional de Arquivos (SINAR).

\subsubsection{DECRETO 1173 CONSELHO NACIONAL DE ARQUIVO E SISTEMA NACIONAL DE ARQUIVO}

El 29 de junio de 1994 fue promulgado el decreto 1173 del CNA, establece que éste es un órgano colegiado vinculado al AN y es el que dispone sobre las políticas nacionales de archivos de los sectores públicos y privados. Las competencias más relevantes son las siguientes:

- Establecer las directrices para el funcionamiento del SNA; promover la interacción de los archivos públicos y privados con vistas al intercambio e integración sistemática de las actividades archivísticas.

- Proponer ante el Ministerio de Estado de Justicia dispositivos legales necesarios para el perfeccionamiento e implementación de políticas nacionales de archivos. 
- Vigilar por el cumplimiento de los dispositivos constitucionales y legales de funcionamiento y acceso a los archivos públicos.

- Estimular la gestión y preservación de los documentos públicos.

- Estimular la integración y modernización de los archivos públicos y privados.

- Declarar de interés público y social los archivos privados que contengan fuentes relativas para la historia nacional.

- Estimular la capacitación de los recursos humanos que desarrollen actividades de archivos en instituciones integradas al sistema.

Hay que destacar que el decreto contempla la integración de cámaras técnicas o comisiones especiales ${ }^{37}$ con la finalidad de elaborar estudios y normas necesarias para la implementación de políticas nacionales de archivos, públicos y privados, y para el funcionamiento de SNA.

Por otra parte, el mismo decreto establece en el art. 10 que el SNA "tiene por finalidad implementar la política nacional de archivos públicos y privados; así como, la gestión, preservación y acceso a los documentos de los archivos"38. Además, tendrá como órgano central al CNA y estará integrado por el AN, los archivos del Poder Ejecutivo Federal, del Poder Legislativo Federal, del Poder Judicial Federal, del Distrito Federal, los municipales y las personas físicas y jurídicas de ámbito privado detentoras de archivos que se integren al Sistema mediante convenio con el órgano central.

Las atribuciones más relevantes del SNA son las siguientes:

\footnotetext{
${ }^{37}$ Aunque el decreto no indica cuáles son esas comisiones, otras fuentes (J. Antunes da Silva. A política Nacional de Arquivos, 1977, pág. 18) nos lo han revelado, estas son: Câmara Técnica de Classificaçã de Documentos, Câmara Técnica de Avaliação de Documentos, Câmara Técnica de Documentos Electrõnicos, Câmara Técnica de Conservação de Documentos, Câmara Técnica de Capacitação de Recursos Humanos, Comissão Especiales para Revisão da Legislação sobre Microfilmagen, Comissão Especial de Acceso à Informação de Arquivos, Comissão Especial de Terminologia Arquivística y Comissão Especial para Regulamentação la Lei de Arquivos quanto oas acervos públicos, privados de carácter público e privados de interesse públicos e social.

${ }^{38}$ Archivum, 1995, pág. 85
} 
- Promover la gestión, preservación y acceso a la información de la esfera de sus competencias, en conformidad con las directrices y normas emanadas del órgano competente.

- Implementar la racionalización de las actividades archivísticas de forma que garantice la integridad del ciclo vital de los documentos.

- Garantizar la custodia y acceso de los documentos de valor permanente.

- Promover la integración y modernización de los archivos de su esfera de actuación.

- Promover al órgano central los archivos privados que puedan ser considerados de interés público y social.

\subsection{EL SISTEMA NACIONAL DE ARCHIVOS DE COLOMBIA}

El SNA colombiano tiene su génesis en la ley 80, de 22 de diciembre de 1989. Señala como parte de las funciones del AGN establecer, organizar y dirigir el SNA, con el fin de planear y coordinar la función archivística de toda la Nación, salvaguardar el patrimonio documental del país y ponerlo al servicio de la comunidad. Además, apunta que el AGN debe formular, orientar, coordinar y controlar la política nacional de archivos en consonancia con el plan nacional de desarrollo.

Los anteriores postulados, que fueron la primicia del SNA de Colombia, esbozan la preocupación por establecer políticas nacionales en materia archivística, pero sin entrar en mayor especificación. Únicamente aborda la situación como tal, pero a pesar de ello, deja una base bastante sólida para continuar en lo sucesivo con ese planteamiento. Cabe destacar que desde un inicio se estableció al AGN como cabeza del Sistema. 


\subsubsection{DECRETO 1777 ESTATUTO DEL ARCHIVO GENERAL DE LA NACIÓN}

La promulgación del decreto 1777, de 3 de agosto de 1990, le da mayor relevancia al SNA; el art. 3, inc. a, menciona que el AGN tendrá como objetivos “...organizar y dirigir el SNA con la adopción de sistemas, procedimientos y normas técnicas que modernicen la gestión de los archivos de la administración pública como centros de información y con la formación de recursos humanos para el manejo de archivos" 39 .

De lo anterior, hay que destacar dos aspectos. En primer lugar, la nueva concepción que se le da a los archivos, destierra por completo la tradicional noción de éstos como depósitos de documentos y custodios del pasado. Le asigna, por lo tanto, una nueva postura más integral, más moderna; los archivos como verdaderos centros de información al servicio de los ciudadanos. El segundo aspecto, hace hincapié en la necesidad de la formación atinente del personal encargado de los archivos, es decir, los archiveros; condición imprescindible para la oportuna administración de cualquier archivo.

Otro argumento novedoso es que le atribuye al AGN la coordinación de las instituciones archivísticas que integran el SNA para que sean factores de desarrollo cultural del país, en armonía con el plan nacional de desarrollo económico y social. Desafortunadamente no ahonda más en el planteamiento, por lo tanto, deja un vacío sustancial sobre las actividades culturales por desarrollar.

El art. 14 establece que el SNA tiene como misión: "salvaguardar el Patrimonio Documental de la Nación y ponerlo al servicio de la comunidad"40. Además, procurará la modernización del ámbito archivístico nacional y buscará armonizar la acción de las instituciones en esa actuación. Así mismo, propiciará la integración de los archivos al Sistema y contribuirá en su organización técnica.

\subsubsection{ACUERDO 07 REGLAMENTO GENERAL DE ARCHIVOS}

\footnotetext{
${ }^{39}$ Archivo General de la Nación de Colombia. Reglamento General de Archivos, 1994, pág. 62.

40Ibídem, pág. 66.
} 
El 29 de junio de 1994 fue promulgado el acuerdo 07, referido al reglamento general de archivos, como norma reguladora del quehacer archivístico de Colombia. Establece que las etapas del archivo, acorde con el ciclo vital del documento, que se presentan en ese país son tres, a saber, gestión, central, e histórico.

La aplicabilidad de este reglamento tiene su campo de acción en todos los archivos oficiales de orden nacional, departamental, distrital, municipal, de las entidades territoriales indígenas y de los archivos históricos especiales ${ }^{41}$; en síntesis, abarca todos los archivos del sector público.

De nuevo manifiesta que el AGN es la entidad encargada de dirigir y coordinar la función archivística en el contexto nacional; así como, el rector y responsable de todo lo relacionado con las políticas en cuestión.

A raíz de la explosión documental y la necesidad de buscar mecanismos técnicos y objetivos para aplicar el expurgo, contempla la creación del Comité Evaluador de Documentos. Éste será el encargado de estudiar los asuntos pertinentes a su valor secundario y de preparar las políticas de selección y eliminación.

Un aspecto trascendental es que dispone la creación de un comité de archivos. Cada entidad establecerá una comisión, que tendrá la función de asesora, para la elaboración de los programas de trabajo y de toma de decisiones en los procesos administrativos y técnicos del archivo. Este grupo es el responsable de dictar y dirigir las políticas archivísticas internas, además de velar porque se cumplan las emanadas por el ente rector. También tienen la responsabilidad de valorar la documentación de la entidad, previa al Comité Evaluador de Documentos y aprobar las tablas de retención.

Otro aspecto que considera es la conveniencia de realizar las transferencias de documentos de un archivo a otro. Los que hayan cumplido su primera y segunda edad, así como, el proceso de expurgo y que ameriten su conservación permanente, deberán ser remitidos -mediante un acta de entrega- al archivo que corresponda debidamente identificados. El profesor Romero Tallafigo señala que un buen sistema de hojas o relación de entrega deben garantizar con eficacia una serie de operaciones que

\footnotetext{
${ }^{41}$ La ley no especifica qué se entiende por archivos históricos especiales.
} 
garanticen saber y autorizar lo que se recibe, junto con la integración plena de los documentos en el sistema de conservación física y el sistema u organigrama memoria ${ }^{42}$.

El respeto del fundamento básico de la teoría archivística, constituye un elemento de primer orden para realizar la clasificación. El acuerdo dictamina que ésta debe hacerse con un criterio orgánico funcional, teniendo como base la estructura orgánica de cada entidad y respetando el principio de procedencia.

La relación con los archivos privados está limitada a la custodia de éstos en los depósitos de los archivos públicos; con el previo consentimiento de las partes implicadas y acatando la normativa vigente.

El fin último de todo archivo es facilitar la información, brindar un eficaz servicio a los clientes internos y externos. La elaboración de un programa descriptivo permite la pronta recuperación de los datos, tal como lo indica el profesor Cruz Mundet, la descripción de los documentos constituye la parte culminante del trabajo archivístico y viene a coincidir exactamente en su finalidad con la de la propia documentación: informar $^{43}$. Los instrumentos descriptivos, que estipula el acuerdo, por utilizar en los archivos son: las guías, los inventarios, los catálogos y los índices. Contempla únicamente aquellas herramientas convencionales, no hace mención a su automatización ni a la aplicación de las normas internacional de descripción ISAD (G) e ISAAR (CPF).

Todo ciudadano tiene derecho al acceso de la documentación que custodian los archivos públicos; salvo excepciones, ésta será restringida o se negará su uso, por ejemplo cuando se aténte contra la seguridad del Estado, afecte la intimidad de las personas o por razones de conservación. Con relación a este último caso, el reglamento establece en el art. 43 que: "cuando el mal estado de conservación de los documentos impida su acceso directo, las instituciones archivísticas suministrarán la información contenida en éstos mediante cualquier sistema de reproducción, certificando su autenticidad cuando fuere el caso..." 44.

Por último, contempla la conservación preventiva de la documentación desde una perspectiva integral, ya que abarca aspectos de infraestructura, sistemas de

\footnotetext{
${ }^{42}$ M. Romero Tallafigo. Op. Cit., pág. 397.

${ }^{43}$ J. R. Cruz Mundet. Op. Cit., pág. 225.
} 
almacenamiento y seguridad, entre otros. Todo ello con el objetivo de evitar, detener y corregir el deterioro que afecte la integridad física de los documentos, desde el momento de su gestación hasta su disposición final, es decir, durante todo su ciclo vital.

\subsection{EL SISTEMA NACIONAL DE ARCHIVOS DE COSTA RICA}

Los antecedentes del SNA costarricense se remontan al año de 1972, cuando éste participó en la Conferencia Interamericana sobre Archivos, celebrada en Washington. Situación que le permitió una mayor concienciación para un cambio de postura y, en consecuencia, un replanteamiento de las políticas archivísticas del país.

Otro elemento que posibilitó esa conmutación fue la creación, en 1966, de la ley del Archivo Nacional ${ }^{45}$; que además de regular el funcionamiento de este archivo final, también legislaba de forma incipiente los aspectos relativos a un futuro SNA.

Posterior a la citada conferencia, Costa Rica participó en programas para el desarrollo de archivos auspiciado por la Organización de los Estados Americanos (OEA) y la Organización de las Naciones Unidas para la Educación, la Ciencia y la Cultura (UNESCO), los cuales enviaron especialistas a esta Nación con el objetivo de asesorar y dar pautas en la organización de los archivos, acorde con las técnicas y normativa de la teoría archivística moderna.

En el año de 1975 la UNESCO estableció un "Proyecto Piloto para el Desarrollo de Archivos de Costa Rica", lo que permitió -años después- la creación de una nueva legislación y reglamentación archivística para el establecimiento de un SNA; a razón de que la forma ideal de organización de los archivos de un país es mediante un sistema de archivos públicos, privados y particulares si es factible, con un marco jurídico adecuado $\mathrm{y}$ un ente rector que procure una unidad de régimen, por contarse con normas, disposiciones y autoridad comunes ${ }^{46}$.

\footnotetext{
${ }^{44}$ Archivo General de la Nación. Op. Cit., pág. 28.

${ }^{45}$ Derogada años después por la actual ley 7202.

${ }^{46}$ V. Chacón. Legislación Archivística, 1991, pág. 62.
} 
Paralelo a ésta gran iniciativa se produjeron otros acontecimientos que, directa o indirectamente, favorecieron en la creación del actual SNA. Entre ellos tenemos los siguientes:

- La promulgación, en el año de 1974, de la ley de la Junta Administrativa del Archivo Nacional, cuyo objetivo primordial era coordinar los programas de la entidad y promover la construcción del nuevo edificio del AN.

- La creación, en el año de 1978 de la carrera -a nivel de pregrado- de Archivo Administrativo ${ }^{47}$, encargada de la formación académica de los profesionales de los archivos.

- El establecimiento de programas de capacitación en archivos de gestión y centrales, dirigidos por el AN.

- El adiestramiento de funcionarios públicos a través de cursos cortos, charlas, jornadas y seminarios, entre otros.

- El incremento cualitativo y cuantitativo de los recursos humanos del AN.

Estos factores contribuyeron ha concentrar esfuerzos por una causa en común, buscar los mecanismos necesarios para la mayor y mejor integración de todos los archivos del sector público, con miras al perfeccionamiento de su entorno. Todo ello bajo la rectoría de un órgano competente y de reconocido prestigio por su capacidad y experiencia, y con un marco jurídico que lo respaldara.

Después de un arduo trabajo por parte de un equipo entusiasta y preocupado por la archivística nacional, se redactó el proyecto de ley del SNA; el cual, tras innumerables luchas ante el Congreso, fue aprobado mediante la ley 7202. Cinco años más tarde le correspondió al reglamento que regula la ley mediante el decreto 24023-C.

\subsubsection{LEY 7202 SISTEMA NACIONAL DE ARCHIVOS}


El 24 de octubre de 1990 se aprobó la ley 7202 que dio origen al Sistema Nacional de Archivos de Costa Rica, compuesta por el conjunto de archivos públicos del país y por los privados y particulares que se integren a él.

La ley señala que todos los documentos con valor científico-cultural, son bienes muebles y forman parte del patrimonio del país; éstos son: textuales, manuscritos o impresos, gráficos, audiovisuales, legibles por máquina que por su contenido sirven como testimonio y reflejan el desarrollo de la realidad costarricense. Estos documentos tienen que ser custodiados en los diversos archivos centrales públicos; una vez cumplidos los plazos de retención, serán transferidos al AN.

Una actuación bastante frecuente, pero deplorable, de los políticos es que al término de su gestión pretenden llevarse la documentación que han generado como funcionarios públicos, atribuyéndosela como de su propiedad. Actuación que los hace incurrir en un hecho de apropiación ilícita, pues esos documentos que han recibido o producido, son el producto de las funciones y actividades que el Estado les ha encomendado; por lo tanto, forman parte del PDN y son propiedad de todos los ciudadanos.

Para evitar situaciones tan lamentables como la anterior, todos los documentos producidos en las instituciones estatales, como producto de su cometido, será propiedad de esa entidad durante su gestión y su permanencia tendrá lugar en el archivo central ${ }^{48}$; por lo tanto ninguna persona o funcionario podrá apropiarse de ellos, posteriormente formarán parte del fondo documental del AN.

Todo ciudadano tiene derecho al libre acceso a la documentación que produzcan o custodien las instituciones públicas, salvo cuando ésta sea declarada secreto de Estado o de acceso restringido. En estos casos el art. 10 dictamina que para poder acceder a este tipo de información, tienen que haber transcurrido treinta años después de su

\footnotetext{
${ }^{47}$ Años después cambió su nombre por Archivística, actualmente tiene el rango de Sección de Archivística y está adscrita a la Escuela de Historia de la Universidad de Costa Rica. Actualmente ofrece el grado académico de bachillerato.

${ }^{48}$ Salvo la Presidencia de la República y los ministros de Estado, que al terminar sus funciones entregarán al AN los documentos de sus despachos que hayan concluido su trámite de gestión. Dicha transferencia deberá realizarse a más tardar durante la semana anterior al traspaso de poderes.
} 
emisión, siempre y cuando sea para fines de investigación de carácter científico y no irrespete otros derechos constitucionales.

El art. 11 señala que la Junta Directiva del AN será la máxima autoridad del SNA y actuará como órgano rector de éste. Tendrá como objetivo principal mantener una estrecha relación archivística y técnica entre los archivos del Sistema. Respecto a sus funciones más notables destacan las siguientes:

- El establecimiento de las políticas archivísticas del país y recomendar estrategias para un adecuado desarrollo del SNA.

- Formular recomendaciones técnicas sobre la producción y la gestión de documentos.

- Velar por la óptima organización de los archivos públicos.

- Organizar congresos, seminarios, jornadas o actividades similares en las que participen archivistas nacionales e internacionales y otros especialistas o técnicos en ciencias afines a la Archivística.

En Costa Rica no existe un archivo intermedio como tal, por la naturaleza archivística del país esa función la asumen, parcialmente, los archivos centrales de las corporaciones estatales y el AN. Al respecto el art. 30 indica que: "La Dirección General del Archivo Nacional es un archivo final. Asumirá, además, las funciones de un archivo intermedio, para lo cual contará con los servicios administrativos necesarios" 49 .

El art. 31 establece la creación de la Comisión Nacional de Selección y Eliminación de Documentos, encargada de dictar las normas sobre el expurgo. La componen el presidente de la Junta Administrativa del Archivo Nacional, el jefe del Departamento Documental del AN, un técnico de ese departamento, el jefe o encargado del archivo de la entidad productora de la documentación y un reconocido historiador.

\footnotetext{
${ }^{49}$ Ministerio de Cultura, Juventud y Deportes. Ley del Sistema Nacional de Archivos, 1996, pág. 11.
} 
La anterior disposición no tiene en cuenta a los juristas, administrativistas y los usuarios. Es conveniente considerarlos para obtener diversos criterios sobre un asunto tan delicado como el expurgo y poder llegar a determinaciones lo más atinadas posibles.

Un aspecto distintivo es que contempla la creación de los comités institucionales de selección y eliminación en las diversas entidades que forman parte del Sistema. Estarán integrados por el jefe del archivo, el superior jerárquico de la institución y el asesor jurídico; de nuevo se omite a los administrativistas y a los usuarios. Tienen como funciones evaluar y determinar el valor primario y secundario de los documentos. Por otra parte, la eliminación de la documentación solo puede realizarse con la aprobación de la Comisión Nacional; los que transgredan la ley serán penados con prisión.

Respecto a la transferencia documental menciona que toda institución pública remitirá al AN aquella documentación, custodiada en el archivo central, que haya adquirido valor secundario.

Un aspecto interesante es que las instituciones que se hagan cargo de la documentación de otra entidad pública o privada, deberán mantener esta documentación respetando el principio de procedencia. Además, si estas desaparecieran, por la causa que fuera, deben entregar su documentación y los respectivos instrumentos de descripción directamente al AN. De esa forma se evita la pérdida de parte de la memoria histórica documental del país.

En cuanto a los archivos privados y particulares, los primeros son aquellos que custodian documentos producidos por organizaciones de carácter privado. Los segundos, corresponden a los que conservan documentos producidos o recibidos por una persona o familia. En ambos casos son propiedad privada de quien lo resguarda, pero éstos podrán organizarse con el asesoramiento del $\mathrm{AN}$ y, si lo desean, formar parte del SNA. De ser así, tendrán los mismos derechos y deberes que los públicos; entre ellos, transferir los documentos al AN para que formen parte del PDN.

\subsubsection{DECRETO 24023-C REGLAMENTO A LA LEY DEL SISTEMA NACIONAL DE ARCHIVOS}


El decreto 24023-C, de 30 de enero de 1995, da origen al reglamento que regula la ley 7202. El art. 6 ratifica a la JAAN como órgano rector del SNA y encargado de formular las políticas archivísticas del país. Por su parte, la dirección del AN tiene la función técnica especial de ejecutar esas políticas.

El departamento documental del AN es el responsable de asesorar la reorganización o creación de los archivos de gestión y centrales. Además, de inspeccionar periódicamente su labor y adiestrar al personal que labora en ellos.

Todos los archivos que forman parte del Sistema deben agrupar en sus oficinas y repositorios los documentos producidos o recibidos como resultado de las funciones y actividades encomendadas. Los archivos centrales son los responsables de reunir y custodiar los documentos emanados por los archivos de gestión.

Los documentos serán transferidos a sus respectivos archivos y su período será fijado en la tabla de plazos de conservación. La remisión debe realizarse con la documentación debidamente clasificada y acompañada por la respectiva lista de remisión por triplicado. Una copia se devolverá como recibo a la oficina o entidad correspondiente, otra formará parte del registro general de ingresos y la tercera se incorporará a la nómina que se lleva de la oficina o entidad remitente.

Los documentos deben ser enviados en perfecto estado de limpieza y el personal correspondiente se encargará de confrontar los documentos con la lista de remisión; Cruz Mundet y Mikelarena Peña nos dicen que las oficinas remiten al archivo su documentación ordenada, en cajas numeradas y con una relación de entrega cumplimentada. No se trata de un simple traslado de papeles de un local a otro, sino de conseguir que continúen al servicio de todos, de las administraciones y de los ciudadanos, además de ser garantía para todos sobre el buen funcionamiento del circuito documental ${ }^{50}$.

La conservación de los documentos consiste en evitar, detener y reparar el deterioro y los daños sufridos, incluyendo la aplicación de métodos y técnicas de preservación y restauración. Para que esto proceda, el AN asesora y adiestra a todos los

50J. R. Cruz; F. Mikelarena. Información y documentación administrativa, 1998, pág. 257. 
archivos del Sistema, ya que la conservación preventiva de éstos es una actividad de primer orden para lograr su perpetuación.

El art. 79 define la clasificación como: "La técnica mediante la cual se identifican y agrupan documentos semejantes con características comunes, de acuerdo con un plan establecido previamente" 51 . Los sistemas por utilizar para la elaboración del cuadro de clasificación pueden ser, orgánico, funcional y asunto o materia.

Por su parte, el art. 82 precisa la ordenación como: "La asignación de números o letras que se le dan a los documentos, así como su colocación en el espacio físico correspondiente".52 Este planteamiento es ambiguo porque no deja claro en que consiste esa actividad, ni los métodos de ordenación por utilizar. Entonces, la ordenación es una tarea material consistente en relacionar unos elementos con otros de acuerdo con un criterio establecido de antemano, bien sea la fecha, las letras del alfabeto, los números...se aplica sobre diversos elementos o en diferentes niveles: los documentos, los expedientes, las series, etc. ${ }^{53}$.

Por otra parte, la definición de ordenación que establece la ley, conduce a confusión porque considera la ubicación topográfica de los documentos como parte de la ordenación. Aunque tienen una relación muy estrecha son procesos diferentes

El art. 84 define la descripción como: "El proceso que realiza el archivista para elaborar los instrumentos que facilitarán el conocimiento, el control y el acceso a los fondos documentales" 54 . Todos los archivos que forman parte del Sistema deben elaborar sus programas descriptivos, los de gestión darán prioridad al registro de entrada y salida de documentos, las listas de remisión y las tablas de plazos de conservación. Los centrales a los inventarios y las listas de remisión. Los históricos a las guías e inventarios.

Esta regulación queda incompleta porque, en primer lugar, plantea únicamente la elaboración y aplicación de los instrumentos descriptivos convencionales; no considera las normativas de descripción internacional ISAD (G) e ISAAR (CPF). En

\footnotetext{
${ }^{51}$ Ministerio de Cultura, Juventud y Deportes. Op. Cit., 41.

52 Ibídem, pág. 41.

53J. R. Cruz; F. Mikelarena. Op. Cit., pág. 230.

${ }^{54}$ Ministerio de Cultura, Juventud y Deportes. Op. Cit., pág. 42.
} 
segundo lugar, no hace alusión a la automatización de los instrumentos tradicionales y ni a la aplicación de las tecnologías de la información y comunicación para la recuperación los datos.

Nuevamente menciona la Comisión Nacional de Selección y Eliminación, pero esta vez le atribuyen más funciones, entre ellas, analizar y aprobar las tablas de plazos de conservación de las instituciones que forman parte del Sistema y autorizar la eliminación de los documentos que carezcan de valor científico-cultural. Todas las entidades productoras de documentos son las responsables de fijar la vigencia administrativa y legal de éstos, la Comisión únicamente determinará el valor secundario.

Las instituciones que hayan elaborado las tablas de plazos y, por ende, aprobadas por la Comisión, pueden eliminar la documentación autorizada sin consultar de nuevo a ésta. Pero, dichas tablas deben someterse a revisión por parte de las dos comisiones -nacional e institucional- cada cinco años, para determinar si los criterios emitidos aún son válidos.

El reglamento considera previsiones ante una actividad muy delicada como es la eliminación, el art. 136 recomienda que los documentos por eliminar deben transformase en material no legible, utilizando diferentes técnicas como la incineración, trituración y otros similares. Todo esto garantiza salvar la confidencialidad y evitar cualquier utilización indebida.

En estos tiempos de globalización y reestructuración estatal es frecuente que algunas entidades se fusionen o desaparezcan, con ello la memoria institucional. Para evitar esta situación, el art. 151 dispone que: "En el caso de que una institución desaparezca, fuera absorbida por otra o se convierta en una firma de derecho privado, deberá comunicarlo a la Dirección General del Archivo Nacional con un mínimo de tres meses de antelación, para asesorarla en cuanto a la transferencia y conservación del material archivistico,"55.

Como se indicó en su oportunidad, una de las funciones del SNA es brindar asesorías para la creación o reorganización de archivos centrales; para tal efecto la única 
condición que se pone es que la institución solicitante deberá temer el espacio físico necesario para el archivo, el mobiliario correspondiente y los recursos humanos necesarios. De esta forma se asegura, en parte, su viabilidad y resultados positivos, que la falta de éstos requisitos no sean la causa del fracaso del proyecto.

El AN recibirá la donación de documentos privados y particulares para su custodia, organización y facilitación. Una vez valorados y determinado su carácter científico-cultural, serán organizados y conservados con el nombre del donante o el que se indicare. Además se respetarán las condiciones de restricción de acceso o similar que indique el donante.

\subsection{EL SISTEMA NACIONAL DE ARCHIVO DE ECUADOR}

La comunidad archivística ecuatoriana consciente de la urgencia de normalizar procedimientos y de contar con un marco jurídico que permitiera el funcionamiento coordinado y técnico de los archivos, emprendieron la tarea de buscar soluciones alternativas. El producto de este esfuerzo en conjunto fue la creación, en 1982, del Sistema Nacional de Archivos de Ecuador, después de largos años de gestión.

\subsubsection{LEY DEL SISTEMA NACIONAL DE ARCHIVOS}

El 16 de junio de 1982 fue promulgada la ley del SNA de Ecuador. Está compuesta por el Consejo Nacional de Archivos, el Comité Ejecutivo de Archivos, la Inspectoría General de Archivos y los archivos públicos y privados. Su objetivo primordial es garantizar la protección y administración del PDN.

El Consejo Nacional de Archivos y el Comité Ejecutivo de Archivos, son los responsables de coordinar y controlar la normalización de los procedimientos en materia archivística. Así mismo, de emitir las directrices necesarias y las normas adecuadas concernientes a las técnicas y sistemas para la correcta conservación, evaluación, control y administración del PDN. 
Por su parte, el CNA podrá proporcionar ayuda técnica y económica a los particulares que posean documentos, que por su importancia pueden formar parte del PDN. Llama la atención lo de la ayuda económica, pero la ley no estipula en qué consiste ni en que término se proporciona.

Las etapas del archivo del entorno ecuatoriano se denominan activos, intermedios o temporales y permanentes; evidentemente relacionados con el ciclo vital de los documentos y en correlación con lo que se conoce -en otros espacios archivísticos- como archivos de gestión, central y final. Esto es un fiel reflejo de los problemas terminológicos y de la falta de normalización al respecto.

\subsection{EL SISTEMA NACIONAL DE ARCHIVOS DE PERÚ}

Después de varios años de continuas gestiones, el 10 de junio de 1991 fue promulgada la ley 25323 que dio origen al Sistema Nacional de Archivos de Perú; posteriormente, en 1992, se emitió el reglamento a la ley y otras normas generales al SNA.

\subsubsection{LEY 25323 SISTEMA NACIONAL DE ARCHIVOS}

La ley 25323, de 10 de junio de 1991, estableció el SNA peruano. Con la finalidad de integrar estructural, normativa y funcionalmente los archivos de las entidades públicas; mediante la aplicación de principios, normas, técnicas y métodos de la archivística moderna. Garantizando con ello la defensa, conservación, organización y servicios del PDN. Las funciones del SNA se disponen en el art. 2 y son las siguientes:

- Contribuir a la eficiente gestión pública y privada en apoyo al desarrollo nacional.

- Cautelar y difundir los valores de la identidad nacional.

- Fomentar la investigación científica y tecnológica a través del servicio de los fondos documentales. 
- Asegurar la uniformidad y eficiencia de los procesos técnicos archivísticos en el país.

El SNA está integrado por el AGN, los archivos regionales y los archivos públicos. El primero es el órgano rector y central del sistema y goza de autonomía técnica y administrativa.

\subsubsection{DECRETO SUPREMO 008-92 JUS REGLAMENTO A LA LEY DEL SISTEMA NACIONAL DE ARCHIVOS}

Por medio del decreto supremo 008-92 JUS, de 26 de junio de 1992, fue aprobado el reglamento de la ley 25323.

Los fines del Sistema son normalizar, organizar, uniformar y coordinar el funcionamiento de los archivos públicos, integrándolos al SNA; así como, propiciar el desarrollo nacional a través de la defensa, conservación, organización y servicio del PDN, como fuente esencial de información.

Al SNA peruano tiene una serie de funciones que serán la base de su desenvolvimiento, estas son:

- Definir políticas y emitir normas sobre protección y defensa del PDN.

- Contribuir a optimizar la gestión pública y privada en apoyo al desarrollo nacional, permitiendo la oportuna toma de decisiones.

- Promover y participar en el fomento de la identidad nacional a través del Patrimonio Documental.

- Propender a la adopción de las normas que aseguren la uniformidad y ejecución de los procesos técnicos archivísticos del país. 
El SNA también contempla la previsión para evitar la apropiación de documentos por parte de los funcionarios, advierte que ellos -sea cual fuese su nivel- no podrán conservar en su poder documentos generados en el ejercicio de sus funciones, están obligados a remitirlos al archivo respectivo.

La accesibilidad a la información que custodian los archivos es uno de sus objetivos capitales. Por lo tanto, todos los documentos albergados en los archivos que forma parte del SNA son de acceso libre a los ciudadanos en general; excepto aquellos que puedan atentar contra los intereses y la seguridad nacional y la privacidad o intimidad personal. Por su parte, los archivos privados que se integren al Sistema estipularán los términos de accesibilidad de la información.

\subsubsection{RESOLUCIÓN JEFATURAL 073-85-AGN-J NORMAS GENERALES DEL SISTEMA NACIONAL DE ARCHIVOS}

Las normas generales del SNA fueron creadas con el objetivo de regular los procesos técnicos archivísticos, a fin de que los archiveros cuenten con los elementos básicos aplicables a los archivos para normalizar la organización y funcionamiento de éstos. Estas normas fueron aprobadas por la Resolución Jefatural 073-85-AGN-J, de 31 de mayo de 1995.

\subsubsection{NORMA GENERAL SOBRE LA ADMINISTRACIÓN DE ARCHIVOS}

La norma indica que la administración de archivos es el conjunto de principios, métodos y procedimientos orientados a lograr una eficiente organización y funcionamiento de éstos. Los objetivos de esta norma son determinar los principios de unidad racional y eficiencia en la administración de los archivos del sector público y brindar servicios de información al Estado, a los ciudadanos y a la investigación. Este último objetivo refleja muy bien la razón de ser de cualquier centro de información y, en este caso particular, de los archivos. 


\subsubsection{NORMA GENERAL SOBRE LA ORGANIZACIÓN DE DOCUMENTOS}

La normativa señala que la organización de documentos consiste en el proceso de desarrollo de un conjunto de acciones orientadas a clasificar, ordenar y signar los documentos de cada entidad. Sus objetivos son:

- Establecer criterios uniformes para la organización de los documentos en los archivos del sector público.

- Mantener organizada la documentación de manera integral y orgánica como producto de las actividades de la administración pública.

- Facilitar la localización de los documentos para la recuperación inmediata de la información.

Establece que la clasificación de los documentos en los archivos de gestión será orgánica funcional. Es decir, el cuadro de clasificación se realizará teniendo como base la estructura orgánica de cada entidad y, a su vez, las funciones y actividades de cada unidad darán origen a las series documentales.

La ordenación por aplicar será de acuerdo al método que mejor se adapte a la documentación; este puede ser alfabético, numérico, cronológica y alfanumérica.

\subsubsection{NORMA GENERAL SOBRE LA DESCRIPCIÓN}

La norma establece que la descripción consiste en identificar, analizar y determinar las características externas e internas de los documentos, con la finalidad de elaborar los auxiliares o instrumentos descriptivos. Tiene como objetivos facilitar la localización de los documentos, garantizar el control del PDN y brindar un eficaz y eficiente servicio de información.

Los auxiliares o instrumentos descriptivos por utilizar son el inventario de transferencia de documentos, inventario de eliminación de documentos, inventario 
general de fondos documentales y la tarjeta de registro de documentos. No menciona sobre su automatización, ni la utilización de la norma internacional de descripción.

\subsubsection{NORMA GENERAL SOBRE LA SELECCIÓN}

Considera la selección de documentos como el proceso archivístico que consiste en identificar, analizar y evaluar todas las series documentales de cada entidad para determinar sus períodos de retención; con base en ello se formulará el Programa de Control de Documentos ${ }^{56}$. Los objetivos son garantizar la conservación de los documentos de valor permanente, permitir la eliminación periódica de los documentos innecesarios y aprovechar y prever la disponibilidad de los recursos de espacio, equipo, material y personal de los archivos públicos.

Las series documentales serán analizadas y evaluadas teniendo en cuenta sus valores administrativos, jurídicos, económicos, científicos, históricos, culturales e informativos, para determinar sus períodos de retención. El AGN es el responsable de autorizar y efectuar la eliminación de los documentos que no tienen valor secundario.

\subsubsection{NORMA GENERAL SOBRE LA CONSERVACIÓN}

La conservación consiste en mantener la integridad física del soporte y del texto de los documentos de cada entidad, por medio de la implementación de medidas de preservación y restauración. Tiene como objetivo garantizar la conservación del Patrimonio Documental.

\subsubsection{NORMA GENERAL SOBRE SERVICIOS ARCHIVÍSTICOS}

Los servicio archivísticos consisten en poner a disposición de los usuarios la documentación de cada entidad con fines de información. Su finalidad en satisfacer oportunamente la demanda de información de la entidad productora y del público en general.

\footnotetext{
${ }^{56}$ El Programa de Control de Documentos es un instrumento que contiene los plazos de retención para la transferencia y/o eliminación de todas las series documentales de cada entidad.
} 


\subsection{ANÁLISIS COMPARATIVO}

De los dieciocho países en estudio únicamente cinco tienen un cuerpo normativo que regula el quehacer archivístico, es decir, un SNA de hecho y de derecho. Si se distribuyen geográficamente esas naciones tenemos que, en América Central sólo Costa Rica tiene esa disposición y en América del Sur gozan de esa normativa Brasil, Colombia, Ecuador y Perú. Más en América del Norte y el Caribe, ninguno lo posee.

El primer país de América Latina en establecer un SNA, de hecho y de derecho, fue Ecuador en la década de los 80. Los demás países lo hacen en los 90, por los tanto, estos Sistemas son relativamente recientes y responden a la necesidad de normalizar y dictar directrices en materia archivística, acorde con los postulados de la teoría archivística y con la realidad inmediata de cada país.

Los aspectos que regulan las leyes son muy variopintos, hacen alusión a funcionamiento, objetivos y alcance del Sistema. Así como, la normalización en la aplicación de los procesos técnicos archivísticos. A su vez, tienen en cuenta otras consideraciones como las etapas del archivo, los archiveros, la difusión, la formación y el acceso; entre otros.

El cuadro 7 presenta la relación de los países del América Latina que tienen SNA; a su vez, una sinopsis de las principales actividades.

\section{CUADRO 7}

LOS SISTEMAS NACIONALES DE ARCHIVOS DE AMÉRICA LATINA

\begin{tabular}{|c|c|c|}
\hline \multicolumn{1}{|c|}{ PAÍS } & \multicolumn{1}{|c|}{ LEYES } & ASPECTOS \\
\hline Brasil & -Decreto 1173 (29-06-94) & -Funciones del CNA y SNA. Formación. \\
\hline
\end{tabular}




\begin{tabular}{|c|c|c|c|}
\hline \multirow[t]{2}{*}{ Colombia } & \multicolumn{2}{|c|}{$\begin{array}{lll}\text {-Decreto } & 1777 \quad(03-08- \\
90) & \\
\end{array}$} & -Atribuciones a SNA. Formación. \\
\hline & 94) & -Acuerdo $07 \quad(29-06-$ & $\begin{array}{l}\text {-Reglamento. Etapas del archivo. Transferencia. } \\
\text { Clasificación. Instrumentos descriptivos. } \\
\text { Archivos privados. Acceso. Conservación. } \\
\text { Archiveros. Formación. Archivo central. }\end{array}$ \\
\hline \multirow[t]{2}{*}{ Costa Rica } & \multicolumn{2}{|c|}{-Ley 7202 (24-10-90) } & $\begin{array}{l}\text {-Acceso. Expurgo. Comisión } \text { nacional } \\
\text { institucional de selección. Transferencia. } \\
\text { Archivos privados y particulares. Archivero. } \\
\text { Formación. Difusión. }\end{array}$ \\
\hline & \multicolumn{2}{|c|}{$\begin{array}{l}\text {-Decreto } 24023-\mathrm{C} \\
(30-01-95)\end{array}$} & 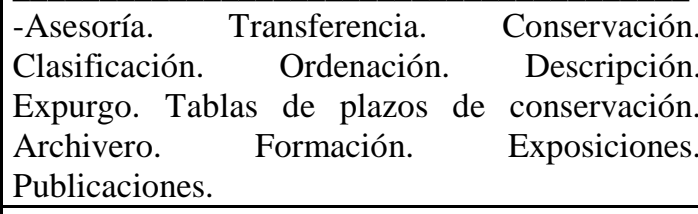 \\
\hline Ecuador & \multicolumn{2}{|c|}{-Ley de 16 de junio de 1982} & -PDN. Etapas del archivo. Normalización. \\
\hline \multirow[t]{3}{*}{ Perú } & $\begin{array}{l}\text {-Ley } \\
91)\end{array}$ & $25323 \quad(10-06-$ & -PDN. Etapas del archivo. Normalización. \\
\hline & $\begin{array}{l}92 \\
92)\end{array}$ & $\begin{array}{lr}\text {-Decreto } & \text { Supremo } 008- \\
\text { JUS } & (26-06- \\
\end{array}$ & -Funciones del SNA. Acceso. Archivero. \\
\hline & \multicolumn{2}{|c|}{$\begin{array}{cc}\text { Resolución } & \text { Jefatural } \\
\text { 073-85-AGN-J (31-05-95) }\end{array}$} & $\begin{array}{l}\text {-Administración. Organización. Descripción. } \\
\text { Selección. Conservación. Servicios. }\end{array}$ \\
\hline
\end{tabular}

Fuente: Elaboración propia a partir de las leyes analizadas.

\section{4- CONCLUSIONES}

Al término de este trabajo hemos llegado a las siguientes conclusiones:

1- Durante el período colonial dio inicio el interés por la organización de la documentación de las instituciones de la época. Surgen los primeros archivos y, en consecuencia, los primeros preceptos legales para regular sus funciones y otros procesos atinentes.

2- Después de la independencia de las colonias y con la formación de los nuevos estados, aumenta el interés por los documentos; en consecuencia, se promulgan nuevas leyes que dan origen a los archivos nacionales. Estos se convierten en los principales repositorios de la memoria documental, son custodios del pasado y el presente de una Nación.

3- Los archivos nacionales necesitaban de un marco jurídico que estableciera su creación y respaldara sus actuaciones; por lo tanto, las primeras leyes que surgen en 
estos países están íntimamente relacionadas con dichos archivos. Algunas fueron derogadas para dar cabida a otras más modernas, acorde con las transformaciones y corrientes teóricas de la Archivística contemporánea. Pero, en otros casos parece que el tiempo se ha detenido, ya que muchas de éstas -a pesar de su antigüedad- aún continúan vigentes y presentan una gran obsolescencia en cuanto a sus planteamientos y aplicación de los procesos técnicos archivísticos.

4- En términos generales, la legislación de los países en estudio se presenta en tres niveles, leyes del archivo nacional o archivo general de la Nación, leyes de carácter específico y las leyes de los Sistema Nacional de Archivos. De todas ellas sobresalen las de los archivos nacionales o archivos generales de la Nación, que regula el funcionamiento de éstos y en algunos casos dictan disposiciones para los demás archivos del país; por lo tanto, tienen un mayor alcance pues legislan para su función interna y normalizan determinados aspectos para otros archivos. En otros casos, fueron promulgadas leyes muy específicas sobre determinadas actuaciones de los procesos técnicos archivísticos, como el expurgo, cuya aplicación afecta todo el conjunto de archivos que existen en el país.

5- El desarrollo legal en materia archivística es desigual en la región. Algunos países como Costa Rica (1990 y 1994), Brasil (1991, 1992 y 1994), Colombia (1989, 1990 y 1994), Panamá (1990), etc., cuentan con leyes relativamente modernas; en otros, como Chile (1928), Guatemala (1968), Nicaragua (1959) y Venezuela (1945) están desactualizadas.

6- El principal problema que presentan la mayoría de las leyes del contexto analizado, es su antigüedad y, por ende, su obsolescencia. Algunas datan de la década de los 20 (Chile), de los 30 (República Dominicana) de los 40 (Venezuela), de los 60 (Cuba y Guatemala) y de los 70 (Uruguay). A pesar de ello, paradójicamente aún están vigentes; lo que obliga a una pronta pronunciación al respecto, para establecer una serie de normativas acorde con los postulados de la teoría archivística y con la realidad inmediata de cada país.

7- Es urgente que estas naciones cuenten con un marco jurídico, en materia archivística, ajustado a los cambios políticos, económicos, sociales, culturales y 
tecnológicos; a su vez, que garanticen una estructura técnica y operativa para fijar, coordinar y controlar la política nacional de archivos.

8- Los únicos países que disponen de una Sistema Nacional de Archivos, de hecho y de derecho, son Brasil (Ley 1173, de 29 de junio de 1994), Colombia (Decreto 1777, de 3 de agosto de 1990 y acuerdo 07, de 29 de junio de 1994), Costa Rica (Ley 7202, de 24 de octubre de 1990 y decreto 24023-C, de 30 de enero de 1995), Ecuador (Ley de 16 de junio de 1982) y Perú (Ley 25323, de 10 de junio de 1991 y decreto supremo 008-92 JUS, de 26 de junio de 1992). Lo cual ha permitido fijar lineamientos acordes con los postulados de la Archivística contemporánea y en consonancia con otras áreas afines; en aras del mejor y mayor desarrollo archivístico, para beneficio de todos los ciudadanos.

9- Los Sistema Nacional de Archivos son relativamente recientes, datan en su gran mayoría de la década de los 90' y están conformados por dos clases de regulaciones, la ley en sí que les da origen y establece su funcionamiento y el reglamento que los regula.

10- Los Sistema Nacional de Archivos se originan como producto de la necesidad y preocupación de dotar a los archivos de un cuerpo normativo que sistematice su funcionamiento y que respalde sus actuaciones. Aunado a ello, la urgencia de modernizar y regular los procesos atinentes a las labores propias de los archivos; teniendo en cuenta para ello los postulados de la teoría archivística contemporánea.

11- El Sistema Nacional de Archivo al contar con una base legal respaldará las acciones por desarrollar y le permitirá una amplia presencia en el ámbito nacional, para garantizar una óptima utilización de los recursos y fomentar una cultura de información archivística en la colectividad. Además, que le permita participar en la regulación de los trámites burocráticos, en la transparencia administrativa, en la lucha contra la corrupción, en el desarrollo cultural, en el progreso integral y en la construcción de una sociedad más democrática y participativa.

12- Por último, entendemos que un aspecto importante por considerar es el factor de impacto de las leyes en cuanto a su aplicabilidad. Por lo general sucede que 
sus disposiciones no van más allá de la teoría y que su puesta en marcha se ve mutilada por el entrabamiento burocrático y la falta de decisión y apoyo de los políticos de turno. Es posible, también, que dada su obsolescencia en algunos países sea habitual regirse por normas que sin el carácter legal funcionan como tal. Ambos planteamiento podrían ser tema de otro artículo o línea de investigación. En éste, tal como señalamos en la introducción, nos hemos limitado únicamente al estudio de la legislación archivística vigente en América Latina.

\section{5- BIBLIOGRAFÍA}

ANTUNES DA SILVA, Jaime. "A política nacional de arquivos". En: Revista $A L A . \mathrm{N}^{\circ} 20$, enero-junio, 1997.

ARCHIVO GENERAL DE LA NACIÓN DE COLOMBIA. Reglamento General de Archivos. Colombia, 1994.

ARCHIVUM. Vol. XVII, 1971.

ARCHIVUM. Vol. XIX, 1972.

ARCHIVUM. Vol. XX, 1972.

ARCHIVUM. Vol. XXI, 1973.

ARCHIVUM. Vol. XXVIII, 1982.

ARCHIVUM. Vol. XL, 1995.

ARCHIVUM. Vol. XLI, 1996.

BRICEÑO PEROZO, Mario. "El Sistema Nacional de Archivos". En: Revista del Archivo General de la Nación de Perú. № 11, 1995.

COUTURE, Carol; LAJEUNESE, Marcel. Législations et politique archivistiques dons le monde. Quebec: Documentor, 1993. 
CRUZ MUNDET, José Ramón; MIKELARENA PEÑA, Fernando. Información y documentación administrativa. Madrid: Tecnos, 1998.

CRUZ MUNDET, José Ramón. Manual de archivística. $2^{\mathrm{a}}$ ed. Madrid: Fundación Germán Sánchez Ruipérez, 1996.

CHACÓN ARIAS, Virginia. "Costa Rica mira por el telescopio". En: Revista $A L A . \quad \mathrm{N}^{\circ} 20$, enero-junio, 1997.

CHACÓN ARIAS, Virginia. "Legislación Archivística Costarricense". En: Revista ALA. Julio-diciembre, 1990.

CHACÓN ARIAS, Virginia. "Legislación Archivística". En: Revista del Archivo Nacional de Costa Rica. Año LV, enero-diciembre, 1991.

CHACÓN DE UMAÑA, Luz Alba. "Implantación del Sistema Nacional de Archivos en Costa Rica". En: Anuario Interamericano de Archivos. Vol. XI, 1984.

DURAND FLORES, Guillermo. "Sistema Nacional de Archivos". En: Revista del Archivo Nacional de Perú. №7, 1984.

FUSTER RUIZ, Francisco. Política y planificación de archivos. Murcia: DN, 1995.

GRUPO DE TRABAJO DE LA ASOCIACIÓN LATINOAMERICANA DE ARCHIVO DE ARCHIVOS Y EL COMITÉ DE ARCHIVOS DEL INSTITUTO PANAMERICANO DE GEOGRAFÍA E HISTORIA. Para una estrategia de desarrollo. Reporte general y principales recomendaciones para la modernización de los sistemas archivísticos de los países latinoamericanos. Julio, 1990.

HEREDIA HERRERA, Antonia. Archivística General. Teoría y práctica. $6^{\mathrm{a}}$ ed. Sevilla: Diputación Provincial, 1993.

JARDÍN, José María. Sistemas e Políticas de Arquivos no Brasil. Niterói: EDUFF, 1995. 
LODOLINI, Elio. Archivística. Principios y problemas. Madrid: ANANAD, 1993.

MARTÍN-POZUELO CAMPILLOS, Ma Paz. La construcción teórica en Archivística: El Principio de Procedencia. Madrid: Universidad Carlos III de Madrid. Boletín Oficial del Estado, 1996.

MEJÍA, Myrian. "Memoria de lo visible". En: Revista ALA. № 20, enero-junio, 1997.

MINISTERIO DE CULTURA DE ESPAÑA. Diccionario de Terminología Archivística. Madrid: DIN Impresores, 1993.

MINISTERIO DE CULTURA, JUVENTUD Y DEPORTES. Ley del Sistema Nacional de Archivos. Costa Rica: Imprenta Nacional, 1996.

MOLINA NORTES, Juana; LEYVA PALMA, Victoria. Técnicas de archivo y tratamiento de documentación administrativa. Madrid: ANABAD Castilla-La Mancha, 1996.

MORALES CAMPOS, Estela. "América Latina y el Caribe". En: Informe Mundial de sobre la Información. Madrid: UNESCO-CINDOC, 1997.

PALACIOS PRECIADO, Jorge; ARIAS ROCA, Victoria. "América Latina y el Caribe. En: Informe Mundial sobre la Información. Madrid: UNESCO-CINDOC, 1997.

PALACIOS PRECIADO, Jorge. "Los colores de la utopía". En: Revista ALA. No 20, enero-junio, 1997.

PALACIOS PRECIADO, Jorge. "Una pasión continental". En: Revista ALA. No 21, enero-junio, 1998.

PÉREZ HERRERO, Enrique. El archivo y el archivero. Islas Canarias-España: Viceconsejería de Cultura y Deporte, 1997. 
RAMÍREZ DELEÓN, José Antonio. "Sistemas Nacional de Archivos: prioridades". En: Foro Archivístico. N 3, enero-junio, 1992.

REAL ACADEMIA ESPAÑOLA. Diccionario de la Lengua Española. 21 ed. Madrid: Espasa Calpe S. A., 1992.

REVISTA DEL SED. Año 3, nº 2, julio-diciembre, 1995.

REVISTA DEL SED. Año 4, nº 2, julio-diciembre, 1996.

REVISTA DEL SED. Año 5, nº 1, enero-junio, 1997.

ROMERO TAlLAFIGO, Manuel. Archivística y archivos. Soportes, edificios y organización. $3^{\mathrm{a}}$ ed. Carmona: S \& C ediciones, 1997.

SALAVARRÍA, Berarda. "El otro oficio de la transparencia". En: Revista ALA. № 20, enero-junio, 1997.

TANODI, Aurelio. "Legislación. Notas sobre la legislación archivística latinoamericana”. En: Anuario Internacional de Archivos. Vol. XI, 1994.

UNESCO. Informe Mundial sobre la Información 1997-1998. Madrid: UNESCO-CINDOC, 1997.

VÁZQUEZ MURILLO, Manuel. Manual de selección documental. $3^{\circ}$ ed. Carmona: S \& C ediciones, 1995. 